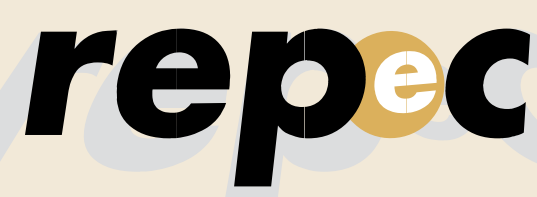

REPeC, Brasília, v. 11, n. 1, art. 1, p. 5-29, jan./mar. 2017

Disponivel online em www.repec.org.br

DOl: http://dx.doi.org/10.17524/repec.v1111.1478

\title{
Comportamento e Particularidades da produção acadêmica do tema "Contabilidade Gerencial" divulgada na base de dados do ISI WEB of Science Core Collection de 1985 a 2014
}

\begin{abstract}
Resumo
O objetivo deste estudo foi analisar o comportamento e as particularidades da produção acadêmica do tema Contabilidade Gerencial divulgada no ISI Web of Science Core Collection de 1985 a 2014. Metodologicamente, esta pesquisa utilizou as técnicas de análise bibliométrica e sociométrica. Os principais resultados foram: evolução do tema a partir de 2007; Accounting, Organizations and Society e Management Accounting Research, que foram os periódicos que mais publicaram sobre o tema "Contabilidade Gerencial"; Lukka, K. foi o autor mais profícuo; University of Turku foi a instituição que se destacou; e os Estados Unidos da América ficou em ênfase na produção do citado tema. Em relação às redes de coautoria, observouse a sua baixa densidade de grau, impactando em uma alta centralidade de grau, tanto no que se refere ao degree como também ao betweenness. E os temas que ficaram em evidência neste estudo foram: educação; ensino e pesquisa contábil; gestão de custos; controle de gestão; gestão estratégica; e sistema de contabilidade gerencial. Conclui-se de maneira macro que este estudo evidenciou informações inerentes e contemporâneas sobre o tema "Contabilidade Gerencial", enfocando em suas nuances o comportamento e as particularidades de sua produção acadêmica, divulgada no ISI Web of Science Core Collection de 1985 a 2014.
\end{abstract}

Palavras-chave: Contabilidade gerencial; Produção acadêmica; Periódicos internacionais; Bibliometria; Sociometria.

\section{Henrique César Melo Ribeiro \\ Doutor em Administração pela Universidade Nove de Julho (Uninove) Professor-Adjunto Nível 1 na Universidade Federal do Piauí (UFPI) \\ Contato: Av. São Sebastião, 2819. São Benedito. Parnaíba-PI. CEP: 64.202-020 E-mail: hcmribeiro@gmail.com}

\section{Vanessa Carvalho Miranda} Tavares

Mestre em Administração / Gestão do Esporte pela Universidade Nove de Julho (Uninove)

Gestora de Recursos Humanos e docente na Faculdade de Mauá (Fama) Contato: Rua Vitorino Dell Antonia, 349. Vila Noemia. São Paulo-SP. CEP: 09.370-570

E-mail: vancmt@yahoo.com.br 


\section{Introdução}

A “Contabilidade Gerencial” é um tema (Riccio, Mendonça Neto \& Sakata, 2007), que envolve o subsídio ao processo decisório e, consequentemente, a tomada de decisão (Küpper, 2009; Beuren \& Macohon, 2011) na elaboração do planejamento e dos sistemas de gestão do desempenho (Wanderley \& Cullen, 2012) e no provimento de competências relacionadas aos relatórios econômico-financeiros e de controle (Guerreiro, Fezatti, Lopes \& Pereira, 2005), assessorando os gestores na formulação e implementação da estratégia empresarial (Lunkes, Feliu \& Rosa, 2012). Pode-se entender com isso que o papel da contabilidade gerencial é focar no processo empresarial estratégico e, com isso, criar valor para a organização (Padoveze, 1999).

Para Guerreiro, Cornachione Júnior e Soutes (2011), a contabilidade gerencial, em seu estágio atual (seu último estágio até agora), identificado desde o início de 1985, enfoca a geração e/ou criação de valor pelo uso efetivo dos recursos, com o uso de direcionadores de criação de valor para os consumidores, acionistas e consequentemente para a organização, fazendo uso da informação isolada ou combinada com outros recursos para assim, criar novos cenários dentro da organização (Ribeiro \& Espejo, 2013).

Ribeiro e Espejo (2013), em sua pesquisa, a qual teve como objetivo analisar as opções temáticas nas teses e dissertações defendidas nos Programas de Pós-graduação Stricto Sensu em Contabilidade no Brasil, no período de 1973 a 2010, realçaram que o grande destaque foi a temática do Balanced Scorecard (BSC); na segunda colocação, apareceu o Economic Value Added (EVA); e as demais apresentaram percentuais menores. Esse resultado compreensível se ponderada a evolução que o BSC representou quando de seu surgimento e o fato de ser "contemporâneo", ou seja, ainda se apresenta em processo de consolidação (Ribeiro \& Espejo, 2013).

Nesse cenário, observa-se que as pesquisas sobre a área contábil (Borba, Murcia, Rover \& Souza, 2009) sobretudo no que se refere à produção acadêmica do tema "Contabilidade Gerencial", vêm tomando uma dimensão alargada no contexto literário- científico nacional, como se pode perceber por meios dos estudos divulgados em periódicos que realçam o tema "Contabilidade Gerencial", como os de Barros, Schckaiban, Gomes e Felin (2008), Cruz, Espejo, Gassner e Walter (2010), Nascimento, Junqueira e Martins (2010), Tavares Araújo e Castro Silva (2010), Lunkes, Rosa, Gasparetto e Baldoino (2011), Lunkes, Feliu, Borba \& Rosa (2012), Oliveira e Boente (2012), Ribeiro e Espejo (2013), Beuren e Hall (2014), Beuren e Nascimento (2014), Kremer, Da Luz, Suave e Lunkes (2014), Lunkes, Gasparetto, Schnorrenberg e Rosa (2014) e Da Silva e Beuren (2015), e por meio das pesquisas que exaltam também a contabilidade gerencial, contudo, não de maneira predominante, são elas: Carvalho, Saraiva Junior, Fezatti e Costa (2010), Colauto e Almeida (2013), Ribeiro (2013), Brizolla, Chiarello e Lavarda (2014), Carmo, Xavier, Pereira e Martins (2014) e Cunha, Santos e Beuren (2015).

Dos estudos que focam a predominância do tema "Contabilidade Gerencial", verifica-se a versatilidade desses no que se refere à produção científica do citado assunto, possibilitando o aferimento de um alargado número de indicadores bibliométricos e/ou sociométricos. Isso acarreta informações interessantes no que tange às nuances que compõem o tema contabilidade gerencial, no contexto nacional e internacional, contribuindo para o seu melhor entendimento e compreensão e de sua importância como temática imprescindível para o campo do conhecimento contábil.

Dessas pesquisas, de maneira geral, os autores buscaram saber como o tema "Contabilidade Gerencial" se propagou e evoluiu, por meio de bancos de dados de congressos nacionais, sobretudo o Encontro Nacional da Associação de Pós-Graduação e Pesquisas em Administração (Enanpad), de revistas nacionais de B1 a A2 e de periódicos internacionais, sendo que destes, saindo de bases de dados do Scopus, ProQuest, Science Direct e do Accounting, Organizations and Society. 
Diante do exposto, e entendendo e compreendendo que a atual pesquisa, além de evidenciar estudos mais recentes sobre o tema "Contabilidade Gerencial", propagando-se, dessa foram, uma notória contribuição, também buscará papers internacionais mediante o banco de dados ISI Web of Science, que, de acordo com Guz e Rushchitsky (2009), é uma das maiores e mais importantes base de dados, em virtude de esta, envolver diversas áreas do saber, difundindo assim estudos científicos. Com isso, essa base de dados é frequentemente utilizada para pesquisa da produção científica de temas na literatura acadêmica global. Diante desse outro fator, contempla-se outra importante e essencial contribuição deste estudo para a literatura acadêmica nacional.

Justifica-se a escolha da base de dados ISI Web of Science por entender que vários estudos acadêmicos a utiliza para a realização de pesquisas bibliométricas como fonte majestosa de informações. Os estudos de Bar-Ilan (2008) e Falagas, Pitsouni, Malietzis e Pappas (2008) empregaram a citada base de dados em suas respectivas pesquisas.

Ainda na base de dados ISI Web of Science, foram feitas investigações nas áreas do conhecimento da saúde, por Zauber, Winawer, O’Brien, Ho, Gottlieb e Stemberg (2012) e de gestão, sobretudo sobre a governança corporativa (Ribeiro, 2014a) e do mesmo tema nos esportes (Ribeiro, Costa \& Ferreira, 2015) e sustentabilidade (Ribeiro, 2014b). Entre outras pesquisas realizadas na base de dados do Web of Science, ressalta-se sua importância no sentido de comparações de conteúdos, temas e/ou campos do saber nos literários científicos disponíveis no contexto acadêmico global.

Diante disso, e sabendo que a divulgação da produção científica de pesquisas acadêmicas é uma das maneiras mais importantes de difusão e socialização do conhecimento científico em escala global (Murcia \& Borba, 2008), realça-se a questão de pesquisa que norteará este estudo, que é: Qual o comportamento e as particularidades da produção acadêmica do tema Contabilidade Gerencial divulgada no ISI Web of Science Core Collection de 1985 a 2014? Nesse contexto, ressalva-se o objetivo deste estudo, o qual busca: analisar o comportamento e as particularidades da produção acadêmica do tema Contabilidade Gerencial divulgada no ISI Web of Science Core Collection de 1985 a 2014.

Justifica-se iniciar o estudo em 1985 por ser o ano do surgimento do último estágio evolutivo da contabilidade gerencial. que ainda dura até os dias de hoje (Guerreiro, Cornachione Júnior \& Soutes, 2011; Teixeira, Gonzaga, Santos \& Nossa, 2011; Oliveira \& Boente, 2012, Ribeiro \& Espejo, 2013).

\section{Fundamentação Teórica}

Esta seção abordará a bibliometria e a sociometria, além do tema contabilidade gerencial.

\subsection{Bibliometria e sociometria}

A bibliometria é um conjunto de métodos de estudo em constante desenvolvimento (Caldas \& Tinoco, 2004). Ressalta-se que a bibliometria é o estudo das características quantitativas da produção científica (Ribeiro, Costa \& Ferreira, 2015) e, consequentemente, de sua disseminação e uso da informação divulgada com emprego de métodos matemáticos e estatísticos (Spinak, 2013). Ela é uma técnica de pesquisa que admite a aferição da produção acadêmica de temas (Souza \& Ribeiro, 2013) e/ou áreas do conhecimento, a fim de contribuir e socializar os conteúdos desses assuntos e/ou campos do saber no ambiente literário acadêmico global (Hid, Nascimento \& Oliveira, 2012).

A bibliometria foca também na contagem de autoria e coautoria, por meio das análises de publicações, citações (Silveira \& Bazi, 2010) e também cocitações (Cronin, 2001). Isso permite a visualização que pode acontecer em diferentes níveis acadêmicos, conjeturando a qualidade dessas publicações (Glänzel, Debbacken, Thijs \& Schubert, 2006) e permeando no cenário internacional (Smith \& Hazelton, 2008). Com isso, é possível saber quais países, territórios, idiomas e áreas de conhecimento se destacam na difusão dessas publicações no contexto científico internacional (Tsai, 2013). 
Os trabalhos de bibliometria consentem a constituição e socialização do conhecimento científico como evidenciado anteriormente, porém Daim, Rueda, Martin e Gerdsri (2006) ressaltam que esse tipo de pesquisa também admite o entrosamento e a melhor apreensão do passado e a predição para pesquisas futuras, inclusive de temas recentes, emergentes e/ou maduros, como prega Ribeiro (2013), além de tolerar um número vultoso de indicadores bibliométricos que permitem e auxiliam estudiosos no juízo e apreensão sobre diversos temas, sem eles, embrionários, em evolução ou legitimados na literatura acadêmica internacional.

A socialização do conhecimento e o desenvolvimento da temática que se quer entender e compreender depende de sua exposição e circulação, mediante a sua publicação e evidenciação em livros e, principalmente, em periódicos científicos (Hoffman \& Holbrook, 1993).

O escopo das pesquisas bibliométricas é de manifestar ao pesquisador um norte e colocá-lo em contato com o que já foi produzido e publicado anteriormente a respeito do tema de pesquisa de interesse (Pádua, 2004). Nesse contexto, Cruz e Ribeiro (2003) realçam que um estudo bibliométrico pode mirar um elemento dos estudos realizados e difundidos anteriormente sobre o mesmo assunto estudado no momento. Também pode identificar e selecionar os métodos e técnicas de pesquisa a serem utilizados, além de fornecer subsídios para estudos futuros, como é o caso dos recentes estudos encontrados sobre o tema ora investigado.

Outra vantagem de se empregar a bibliometria, de acordo com Hayashi, Hayashi, Silva e Maycke (2007) é o fato de apreender o número e frequência das publicações cronologicamente, ou seja, temporariamente permitindo e contribuindo para a avaliação de grupos de pesquisadores, isto é, de estudos e suas respectivas Instituições de Ensino Superior (IES).

Para Michels e Schmoch (2014), houve um crescimento significativo do emprego da técnica de pesquisa da bibliometria com o desígnio de mensuração, investigação, avaliação e análise de temas de interesse em diversas áreas do conhecimento. Essa evolução deu-se em virtude de que as análises anteriormente realizadas sobre esses temas eram meramente subjetivas.

O impacto á concretização de análises bibliométricas na literatura científica global, de acordo com Michels e Schmoch (2014), veio de nações como a Austrália, Noruega, Reino Unido e Espanha. Tais países nortearam a mudança de comportamento dos acadêmicos de maneira positiva (Weingart, 2005; Bornmann, 2010), contribuindo para o melhor entendimento e concepção de temas, de suas respectivas produções científicas e, posteriormente, de suas concomitantes propagações e socializações no cenário acadêmico mundial.

El-Maamiry e Abid Ghauri (2013) complementam que a bibliometria é muito empregada por bibliotecas e pela ciência da informação, contudo influencia significativamente, em outras áreas do conhecimento, pois esses campos do saber aproveitam-se da bibliometria para expor a proeminência de sua respectiva área de atuação no panorama científico global.

Além da bibliometria, o presente estudo enfatiza e realça também de forma comumente a análise de redes sociais por entender e compreender a sociedade como uma estrutura objetiva de indivíduos e suas consequentes relações, buscando assim princípios que regem o funcionamento dos grupos e suas parcerias (Moreno, 1992, 1993). A partir do entendimento dessas relações, passa-se a melhor compreender a conexão entre elas. Tal aspecto é visto como "sociometria".

Os primeiros estudos sociométricos foram realizados a partir de 1932 por Jacob Levy Moreno, que cunhou o termo sociometria em estudos realizados com meninas em Hudson em Nova York. Com isso, Moreno (1951) definiu a sociometria como um método experimental que é estudado pela matemática, aferindo os atributos psicológicos da sociedade, sendo os resultados obtidos por meio da aplicação de métodos quantitativos.

Moreno $(1992,1993)$ explica que, visando à organização e à espontaneidade do ser humano e buscando analisar os princípios que regem o funcionamento dos grupos, chegou à conclusão de que o conjunto das escolhas sociométricas feitas e percebidas por um indivíduo ou uma população constitui o que o autor chamou de átomo social, podendo ser influenciado pela preferência individual e/ou grupal. 
Partes desses grupos se ligam a outros e assim sucessivamente e vão formando as redes sociais ou sociométricas, que são responsáveis pela transmissão de suas opiniões publicamente. Moreno (1993) complementa ainda que esse instrumento possibilita investigar os vínculos entre as pessoas e mapeá-los possibilitando sua compreensão em função do grupo. Conclui-se, com isso, que a Sociometria é a ciência da medida do relacionamento humano (Moreno, Bouza \& Karsz, 1962).

Dessa forma, torna-se relevante o estudo sobre o tema "Contabilidade Gerencial", uma vez que o assunto é maduro e legitimado no cenário acadêmico nacional. Contudo, este estudo versará de maneira conjunta a aferição, investigação e análise dos artigos sobre o tema, mediante a busca na base de dados do ISI Web of Science, que é amplamente aceita e importante no contexto científico internacional (Guz \& Rushchitsky, 2009), versando assim uma forte contribuição para a literatura acadêmica nacional da área, sobretudo, pelo fato de que o citado estudo abordará a contemporaneidade dos artigos divulgados sobre a matéria ora investigada.

Realça-se que, nacionalmente, os estudos na temática "Contabilidade Gerencial" vêm ganhando destaque e adquirindo cada vez mais espaço no meio acadêmico por meio de sua relação com outros temas, como foi possível perceber anteriormente neste estudo. Contempla-se também outra importante justificativa para a realização deste estudo, pois seus achados nortearam temáticas e/ou áreas do conhecimento que se relacionam diretamente com o seu assunto principal contribuindo para seu melhor entendimento, compreensão e futuro fomento e maior difusão no cenário científico nacional.

\subsection{Contabilidade gerencial}

A partir da década de 1960, o tema "Contabilidade Gerencial" se tornou maduro e se legitimou de maneira tangível como uma ciência social. De maneira macro, essa maturação e concretização deu-se em virtude e ênfase do empirismo e do positivismo, que, aliados ao crescimento dos estudos de caso e de campo sobre o citado tema na Europa, impactaram consequentemente em seu estabelecimento como disciplina acadêmica nas universidades (Lunkes et al., 2011; Lunkes, Feliu, Borba \& Rosa (2012).

Outra justificativa da ênfase em investigações sobre a contabilidade gerencial em 1960 pauta-se na decorrência de motivações empresariais, que exigiam novas técnicas e teorias que proporcionassem maior assertividade na direção das organizações ponderando esse novo cenário (Cruz et al., 2010).

Nesse panorama, ressalta-se que a contabilidade gerencial interage com os mais variados procedimentos gerenciais em todas as empresas. Com isso, caracteriza-se a contabilidade como uma instituição universal, em que o papel da contabilidade gerencial evolui e se propaga conforme as necessidades das empresas no mercado corporativo global (Beuren \& Erfurth, 2010). Ressalta-se que, nas últimas décadas, a contabilidade gerencial passou por quatro estágios evolutivos (Ribeiro \& Espejo, 2013).

Ainda segundo Ribeiro e Espejo (2013), os quatro estágios evolutivos da contabilidade gerencial (Figura 1) propostos levaram em consideração que, com o aperfeiçoamento das organizações no mercado financeiro, as práticas de contabilidade gerencial também foram evoluindo e se moldando, pois buscavam suprir as necessidades informacionais e acabavam com isso, por atribuir uma nova realidade aos negócios globais. De maneira geral, percebe-se que a contabilidade gerencial teve fases claramente delimitadas, as quais demonstram suas respectivas abrangências ao longo de suas existências, que serão destacadas a seguir.

O primeiro estágio durou até 1950 e, nesse período, o objetivo principal foi qualificado como a determinação de custo e controle financeiro, por meio de orçamento e contabilidade de custos. Nesse estágio, os principais mecanismos e métodos utilizados foram: orçamentos anuais, controle financeiro e operacional, custeio por absorção e custeio variável (Guerreiro, Cornachione Júnior \& Soutes, 2011; Teixeira et al., 2011). 


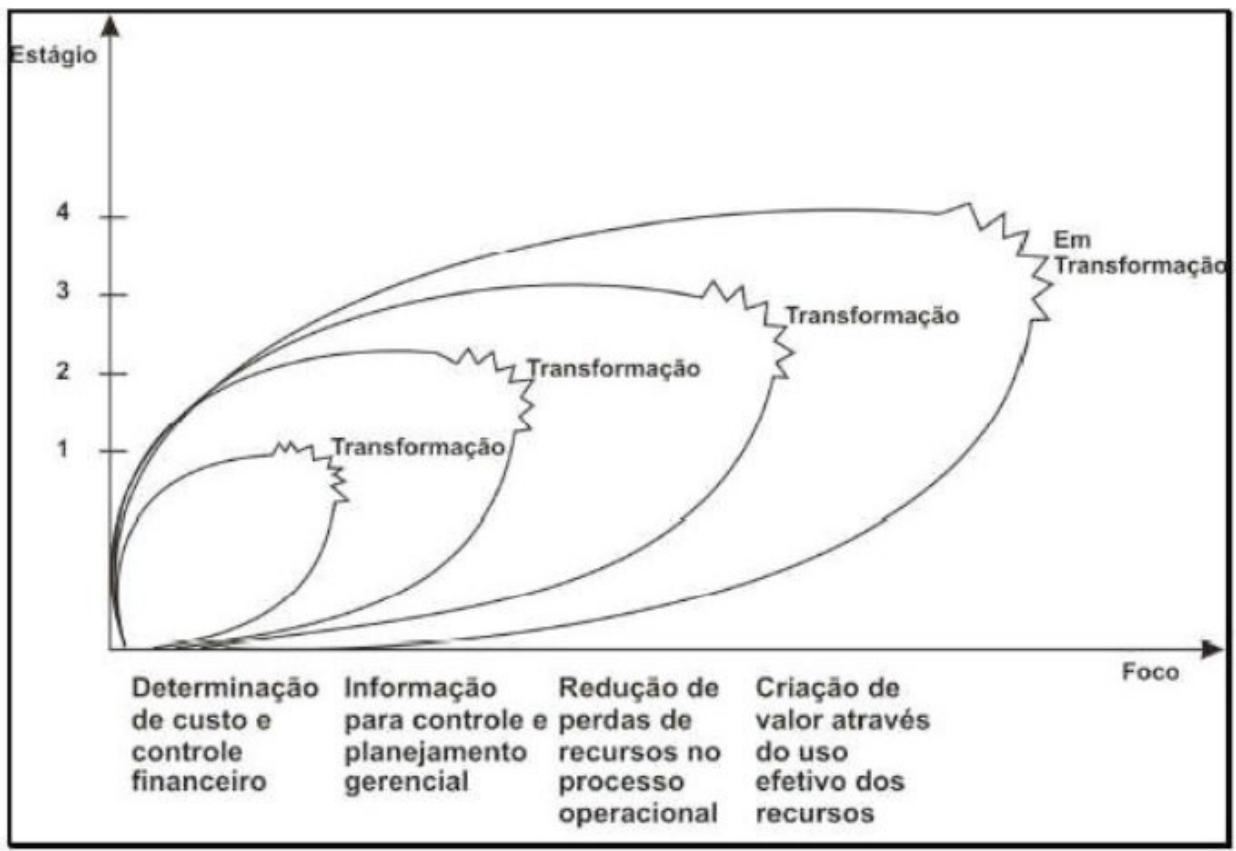

Figura 1.Evolução dos estágios da Contabilidade Gerencial

Fonte: Padoveze (1999).

O segundo estágio foi de 1950 até 1965 e, nesse período, a contabilidade gerencial esteve concentrada no provimento de informação para planejamento e controle gerencial, pelo uso das técnicas de informação de análise de tomada de decisões e contabilidade por responsabilidade. Destacam-se como instrumentos e métodos: custeio padrão, custeio baseado em atividades (ABC), custeio RKW (Reichskuratorium für Wirtschaftlichkei) e descentralização da tomada de decisões (Briers \& Chua, 2001; Guerreiro, Cornachione Júnior \& Soutes, 2011; Teixeira et al., 2011).

O terceiro estágio iniciou-se em 1965 e durou até 1985. Nesse período, a atenção esteve voltada para a minimização de desperdícios de recursos econômicos nos processos e projetos, sendo realçada a análise de processos e gerenciamento de custos, mediante a gestão estratégica. A administração baseada em valor, centros de responsabilidade, preço de transferência, custeio meta, método de custeio kaisen e custeio do ciclo de vida são algumas das ferramentas e metodologias enfocadas nesse estágio (Guerreiro, Cornachione Júnior \& Soutes, 2011; Teixeira et al., 2011).

O último estágio da Contabilidade Gerencial identificado teve início em 1985 e dura até os dias atuais, sendo seu enfoque centrado na geração e/ou na criação de valor pelo uso efetivo dos recursos, com a utilização de direcionadores de criação de valor para o consumidor, valor para o acionista e inovação organizacional (Guerreiro, Cornachione Júnior \& Soutes, 2011). O planejamento estratégico, BSC, método de avaliação de desempenho, EVA e MVA (Market Value Added) são as ferramentas e métodos que se destacam nesse estágio (Teixeira et al., 2011).

É entendido e compreendido que a Contabilidade Gerencial engloba diversos recursos: humanos, físicos e financeiros, de modo que, integrados perfeitamente, contribuem para uma boa gestão da organização. Diante disso, ressalva-se que o mundo dos negócios é competitivo e acirrado, tendo impacto direto no desenvolvimento das empresas que aperfeiçoaram seus sistemas de controle para enfrentar essa concorrência (Oliveira \& Boente, 2012). Nesse panorama, vislumbra-se a contabilidade gerencial, que é essencial e preponderante para desenvolver tais sistemas de controle. 
Em relação ao sistema de controle, ressalva-se o Sistema de Contabilidade Gerencial (SCG) (Chenhall \& Morris, 1986) que é o meio pelo qual a cúpula executiva evidencia as metas e os objetivos da organização aos colaboradores e gerentes de unidades de negócio, sendo assim considerado um canal pelo qual as informações contábeis (Hopp \& Leite, 1988; Oliveira \& Ávila, 1999) sobre o desempenho e a eficiência da organização são divulgadas aos gestores da empresa (Oliveira \& Ávila, 1999), impactando nas tomadas de decisão (Rocha \& Guerreiro, 2010).

Assim, em concordância com o objetivo proposto por este estudo, segue uma perspectiva das pesquisas em contabilidade gerencial, no que tange ao estado da arte de sua produção acadêmica divulgada e publicada em periódicos nacionais.

\subsection{Estudos sobre a produção acadêmica do tema contabilidade gerencial}

É sabido que a publicação da produção acadêmica de estudos científicos é uma das formas essenciais para a disseminação do conhecimento científico de campos do saber e/ou temas científicos (Borba \& Murcia, 2006). E os artigos são essenciais para entender e compreender os fenômenos que norteiam tal conhecimento científico (Ribeiro, 2015). Salienta-se que nos últimos anos, o tema "Contabilidade Gerencial” tem tido significativa expansão em virtude de inúmeras mudanças ocorridas no âmbito econômico, financeiro e social.

Sendo assim, para melhor entendimento e captação da referida temática, vários autores realizaram pesquisas bibliométricas a fim de que mapeassem, investigassem e analisassem o citado tema no contexto literário nacional e internacional, tomando por base bancos de dados diversos, como, de teses e dissertações, anais de congressos, sites de revistas nacionais e bases de dados internacionais. Com isso, contemplam-se a seguir um breve resumo desses estudos nacionais e internacionais, focando seus respectivos objetivos e os seus principais achados.

Luft e Shields (2003) mapearam a pesquisa do tema "Contabilidade Gerencial", mediante 275 artigos publicados em seis periódicos lideres da área. Os autores observaram, por meio das conexões e desconexões da literatura acadêmica, que há um desenvolvimento das pesquisas sobre o citado tema, ajudando assim a contribuir para um melhor entendimento e compreensão das causas e efeitos da contabilidade gerencial no âmbito internacional.

Cruz et al. (2010) identificaram os autores e suas respectivas IES mais relevantes no processo de desenvolvimento do campo da pesquisa em contabilidade gerencial, no período de 2004 a 2008. Nos resultados com relação às IES, tem-se que os principais agentes do campo estão, principalmente, na Universidade de São Paulo (USP). Entre os autores, Antônio A. de Souza se manteve como central no período de 2005-2007, sendo que outros autores também se destacaram em cada período.

Nascimento, Junqueira e Martins (2010) identificaram e analisaram as características epistemológicas da produção acadêmica da pesquisa em contabilidade gerencial no Brasil, de 2005 a 2008. Os resultados indicam: baixa utilização de referências que abordem as teorias da contabilidade gerencial, baixa incidência de referências a artigos publicados em periódicos internacionais e alta idade média dos trabalhos citados - 10 anos. Em relação às teorias, observa-se que $83 \%$ dos trabalhos se baseiam somente em conceitos contábeis ou legislação, enquanto $17 \%$ utilizam teorias da economia, sociologia ou psicologia.

Tavares Araújo e Castro Silva (2010) conheceram alguns aspectos bibliométricos da contabilidade gerencial nos Enanpad entre os anos de 2003-2008. Na pesquisa empírica foram analisados 251 artigos. Verificaram que os autores brasileiros seguem a tendência de replicar os estudos internacionais em contabilidade gerencial, predominamos o tema "Sistema de Controle Gerencial". De maneira geral, percebeu-se que, aparentemente, há carência de pesquisa científica em contabilidade gerencial nos Enanpad. 
Lunkes et al. (2011) analisaram a produção cientifica e a formação de doutores em contabilidade gerencial no Brasil, divulgadas em revistas nacionais e em teses de doutorado, de 1962 a 2010. Os resultados evidenciam um crescimento das publicações sobre contabilidade gerencial. Já a formação de doutores em contabilidade gerencial teve um aumento no período, o que de certa forma, é um reflexo do crescimento na formação de doutores em Ciências Contábeis nos últimos anos.

Lunkes, Feliu, Borba \& Rosa (2012) identificaram e analisaram artigos sobre contabilidade gerencial publicados nas principais revistas e a formação de doutores em contabilidade da Espanha. Os resultados demonstram que as publicações em contabilidade gerencial correspondem a apenas $12 \%$ do total. Já a formação de novos doutores também teve pequena redução, com a formação, até 2010, de 549 doutores, sendo que os formados em contabilidade gerencial representam 20,5\%. De certa forma, menos publicações em contabilidade gerencial acabam afetando os novos doutores em suas opções de pesquisa e vice- versa.

Oliveira e Boente (2012) descreveram e analisaram as principais características do perfil da produção acadêmica do tema "Contabilidade Gerencial" e exploraram 50 artigos científicos nacionais de 2002 a 2010. Os principais achados dessa pesquisa foram: predominância de pesquisa exploratória; o Estado de São Paulo foi a maior localidade de produção científica; e equilíbrio na utilização de referências nacionais e internacionais por artigo.

Ribeiro e Espejo (2013) analisaram as opções temáticas nas teses e dissertações defendidas nos Programas de Pós-graduação Stricto Sensu em Contabilidade no Brasil, no período de 1973 a 2010. Concluíram que, no Estágio 1, predominou-se o custeio por absorção e custeio variável; em relação ao Estágio 2, destacou o orçamento; no Estágio 3, custeio $\mathrm{ABC}$ e planejamento estratégico ficaram em evidência; e, por fim, no Estágio 4, EVA e BSC predominam nas dissertações.

Beuren e Hall (2014) identificaram o perfil dos artigos que utilizaram ou se referiram à estratégia do estudo de caso em pesquisas sobre a prática da contabilidade gerencial publicados em periódicos internacionais em Língua Inglesa. Os resultados da pesquisa mostram que as publicações de artigos desenvolvidos por meio de estudo de caso em contabilidade gerencial tiveram um crescimento no decorrer dos anos analisados, mas com alta concentração em poucos periódicos. A maioria desses artigos relata estudos empíricos, seguindo-se os estudos teóricos e os bibliométricos.

Beuren e Nascimento (2014) analisaram o perfil dos artigos de Contabilidade Gerencial publicados na Accounting, Organizations and Society, no período de 2005 a 2009. Os resultados da pesquisa demonstram, além de características gerais e a autoria dos artigos, que, quanto às disciplinas de base dos artigos pesquisados, a Sociologia sobressaiu-se, seguida de Economia; Produção e Gerenciamento; e Psicologia.

Lunkes et al. (2014) descreveram o desenvolvimento da contabilidade gerencial no Brasil sob a perspectiva da legitimidade sociopolítica e cognitiva. Os resultados mostram, descritivamente que a contabilidade gerencial no Brasil apresenta legitimidade sociopolítica e ainda carece de maior reconhecimento e inserção nos órgãos de representação e de classe, ao passo que, em termos de legitimidade cognitiva, apresenta-se consolidada nas pesquisas em periódicos e congressos, pois possui forte presença em linhas de pesquisa e pesquisadores, apesar de ainda apresentar baixa inserção em disciplinas nas universidades federais.

Da Silva e Beuren (2015) analisaram a produção intelectual sobre a temática de contabilidade gerencial em hospitais publicada entre 1950 e 2011 e testaram empiricamente se está alinhada às leis e aos princípios bibliométricos. Os resultados mostram que os artigos tiveram maior aderência em periódicos da área da saúde comparativamente à área de contabilidade e que os Estados Unidos possuem o maior número (48,5\%) de artigos publicados. Na aplicação empírica das leis de Lotka e de Bradford e dos pressupostos de produtividade, os achados não permitiram confirmar os pressupostos e as leis bibliométricas testadas, o que pode ser um indicativo de não consolidação do tema, com um corpo de autores, instituições e periódicos. 
Analisando os estudos desta seção, observa-se uma gama macro de informações sobre a contabilidade gerencial, nos panoramas nacional e internacional, vislumbrando assim, a importância do citado tema para a difusão, socialização, desenvolvimento e fomento do campo do conhecimento contábil. Entretanto, nenhuma das investigações vistas nesta seção versou sobre a base de dados ISI Web of Science Core Collection de maneira mais aprofundada, alargada e contemporânea, como este trabalho o fez, mostrando assim um diferencial e uma contribuição desta pesquisa em comparação com os estudos divulgados recentemente.

\section{Procedimentos metodológicos}

O objetivo deste estudo foi analisar o comportamento e as particularidades da produção acadêmica do tema Contabilidade Gerencial divulgada no ISI Web of Science Core Collection de 1985 a 2014. Para tanto, utilizou-se das técnicas de análise bibliométrica (Michels \& Schmoch, 2014) e sociométrica (Rostampoor-Vajari, 2012).

Para avaliar a atividade da ciência, a bibliometria baseia-se em leis bibliométricas, das quais ficam em evidência: Lei de Lotka, Lei de Bradford e Lei de Zipf (Da Silva \& Beuren, 2015), ou seja, essas leis alicerçam a bibliometria serão importantes para o melhor entendimento e compreensão das informações que delas necessitarem de maior transparência. Tais leis são: Lei de Lotka, Lei de Bradford e Lei de Zipf (Quadro 1).

Quadro 1

Leis da bibliometria

\begin{tabular}{ccl}
\hline Autor & Lei & Descrição \\
\hline Lotka (1926) & $\begin{array}{c}\text { Lei do } \\
\text { Quadrado } \\
\text { Inverso }\end{array}$ & $\begin{array}{l}\text { A quantidade de autores que publicam n artigos em uma determinada área científica é } \\
\text { aproximadamente } 1 / \mathrm{n} 2 \text { dos que publicam apenas } 1 \text { artigo, e a proporção de autores que } \\
\text { publicam apenas } 1 \text { artigo deve ser } 60 \% \text { do total de autores. Assim, a produtividade dos } \\
\text { autores é mensurada mediante um modelo de distribuição tamanho-frequência dos vários } \\
\text { autores em um grupo de publicações. }\end{array}$ \\
\hline Bradford & Lei de & $\begin{array}{l}\text { Mediante a medição da produtividade das revistas, permite estabelecer o núcleo e as áreas } \\
\text { de dispersão sobre determinado assunto em um mesmo conjunto de revistas. }\end{array}$ \\
\hline Zipf (1949) & Lispersão & $\begin{array}{l}\text { Mensura a frequência do aparecimento das palavras em vários textos, gerando uma lista } \\
\text { ordenada de termos de um determinado assunto. Afirma que, se palavras que aparecem } \\
\text { em um texto de tamanho considerável forem listadas em ordem decrescente de frequência, } \\
\text { a graduação de uma palavra na lista será inversamente proporcional à frequência da } \\
\text { palavra (Pn 1/na). }\end{array}$ \\
\hline
\end{tabular}

Fonte: Tavares Araújo e Castro Silva (2010, p. 36).

Pesquisa bibliométrica de natureza quantitativa, baseada nas Leis de Lotka e Bradford (neste estudo não será utilizada a Lei de Zipf) e em indicadores de colaboração e produtividade dos autores, IES e países, foi realizada mediante a análise de artigos publicados em periódicos indexados na base de dados do ISI Web of Science, nas áreas de Ciências Sociais e Economia e Negócios.

Além da bibliometria, este estudo também focará na sociometria (Ribeiro, 2014c). Um estudo sociométrico ou de análise de redes sociais de relacionamento, como também é conhecido (Cruz et al., 2010), está enfocado na investigação da matriz de relacionamentos constituídos entre atores sociais (GalaskiewicZ \& Wasserman, 1994), representados, neste estudo, pelos autores.

$\mathrm{Na}$ análise de redes sociais, existem quatro elementos basilares que a compõem, são eles: os nós, as posições, as ligações e os fluxos (Wasserman \& Faust, 1994). Os nós são os atores que fazem a rede; as posições são as posições em que esses atores se acham na rede. As ligações acarretam o grau de densidade da rede; e, por fim, os fluxos, são as trocas de informações em uma rede (Wasserman \& Faust, 1994). 
Nesse contexto, os relacionamentos em uma rede são aferidos por pares de atores, independentemente da estrutura e do local onde todos os atores são avaliados (Guimarães, Gomes, Odelins, Zancan \& Corradi, 2009). Ressalta-se que existem diversas maneiras de identificar a estrutura e as interações de uma rede, entre as quais ficam em evidência: o tamanho da rede, a densidade e a centralidade (Wasserman \& Faust, 1994).

A densidade é conceituada como o total de amarrações ativas existentes em determinado grupo de atores, ou seja, um indicante do potencial de comunicação entre os atores da rede (Guimarães et al., 2009). Esse indicador estrutural da rede varia no intervalo de zero a um. Desse modo, quanto mais próximo de zero, menos conectada é a rede social. Porém, quanto mais próximo de um, mais conectados serão os atores de uma rede social (Mendes-da-Silva, Onusic \& Giglio, 2013).

E a centralidade é ponderada como um indicador que calcula a acuidade da localidade de um ator em relação aos outros atores da rede, ou seja, em outras palavras, a quantidade de vinculações que este ator tem com os outros atores (Wasserman \& Faust, 1994).

Três são os graus frequentemente utilizados para se aferir a centralidade de uma rede, a saber: centralidade de grau (degree); centralidade de proximidade (closeness); e a centralidade de intermediação (betweenness) (Ribeiro, Cirani \& Freitas, 2013). Entre essas, coloca-se em ênfase a centralidade de grau, conceituada como o número de laços adjacentes de um ator em relação aos outros em uma rede (Wasserman \& Faust, 1994), contribuindo para melhor estimar a "atividade" posicional dos atores (Rossoni \& Guarido Filho, 2009).

O universo de investigação abarcou todos os artigos das revistas científicas disponibilizadas na base de dados ISI Web of Science Core Collection, sobretudo nas áreas de Ciências Sociais e Economia e Negócios. No que se refere ao ISI Web of Science, os acadêmicos Vieira e Gomes (2009) afirmam que, ela é por anos a base de dados que contempla todos os domínios da ciência.

Os cinco campos do conhecimento escolhidos para a procura dos dados, Ciências Sociais e Economia e Negócios, é em virtude de se crer que as pesquisas sobre contabilidade gerencial possam estar contidas de maneira alargada e robustas nessas citadas áreas.

O procedimento de seleção da amostra aconteceu da seguinte forma: i) escolha das palavras-chave aplicadas no filtro de procura da base de dados; ii) coleta dos dados na base de dados ISI Web of Science Core Collection; iii) busca pelas palavras-chave nos títulos, resumos e palavras-chave dos artigos; iv) definição da amostra, mediante a leitura dos títulos e/ou resumos de cada artigo.

Na base de dados ISI Web of Science Core Collection estabeleceu-se um filtro com a palavra-chave "management accounting". Essa palavra-chave foi procurada no título, resumo e palavras-chave de cada artigo, não simultaneamente, permitindo, assim, que todos os artigos sobre o assunto objeto de estudo desta pesquisa fossem identificados e catalogados.

Depois da definição da amostra, mediante a leitura dos títulos e/ou resumo de cada artigo, deletaram-se papers que porventura pudessem não estar relacionados ao tema principal deste estudo, obtendo-se assim uma amostra composta por 242 artigos, em um recorte temporal dos anos de 1985 a 2014.

Como evidenciado anteriormente, a coleta de dados identificou 242 artigos, que foram analisados, de maneira quantitativa, segundo os seguintes indicadores: (I) evolução do tema contabilidade gerencial; (II) periódicos; (III) autores; (IV) rede social dos autores; (V) IES; (VI) países; (VII) artigos mais citados; e (VIII) temas abordados. Os dados sobre cada artigo foram decompostos em informações e capturados por intercessão do software Bibexcel, e as visualizações das figuras foram feitas por meio dos softwares UCINET 6 for Windows e Microsoft Excel 2007. 


\section{Análise dos resultados e discussão}

Esta seção realiza a análise e discussão dos resultados dos 242 artigos sobre contabilidade gerencial encontrados na base de dados do ISI Web of Science Core Collection em uma temporalidade de 30 anos. A Figura 2 evidencia a evolução do tema "Contabilidade Gerencial” na temporalidade de 1985 a 2014.

Analisando a Figura 2, é visualizado que o tema ora estudado sempre foi difundido nos anos investigados nesta pesquisa, tendo picos de produção, como, por exemplo, no período de 1994 Contudo, é notório que a evolução do tema contabilidade gerencial começou a emergir no ano de 2007, conseguindo ter uma certa constância nos anos subsequentes, destacando-se mais no período de 2010 e sofrendo uma pequena queda em 2012.

Informações evidenciadas aqui, mostram dois comportamentos do tema "Contabilidade Gerencial", ou seja, o primeiro como temática de emergência, durante os períodos de 1985 a 2008; e o segundo como tema maduro e legitimado no contexto científico internacional, entre os anos de 2009 a 2014 . Esse achado contribui para entender e compreender a importância da citada temática, não somente nos anos de 1985 a 2008, mas, sobretudo, durante os anos mais recentes Isso tem influenciado em seu crescimento sustentável, criando valor no âmbito acadêmico internacional, no que tange a difusão e à socialização de sua produção acadêmica, por meio de periódicos científicos internacionais importantes para tal evidenciação e disseminação.

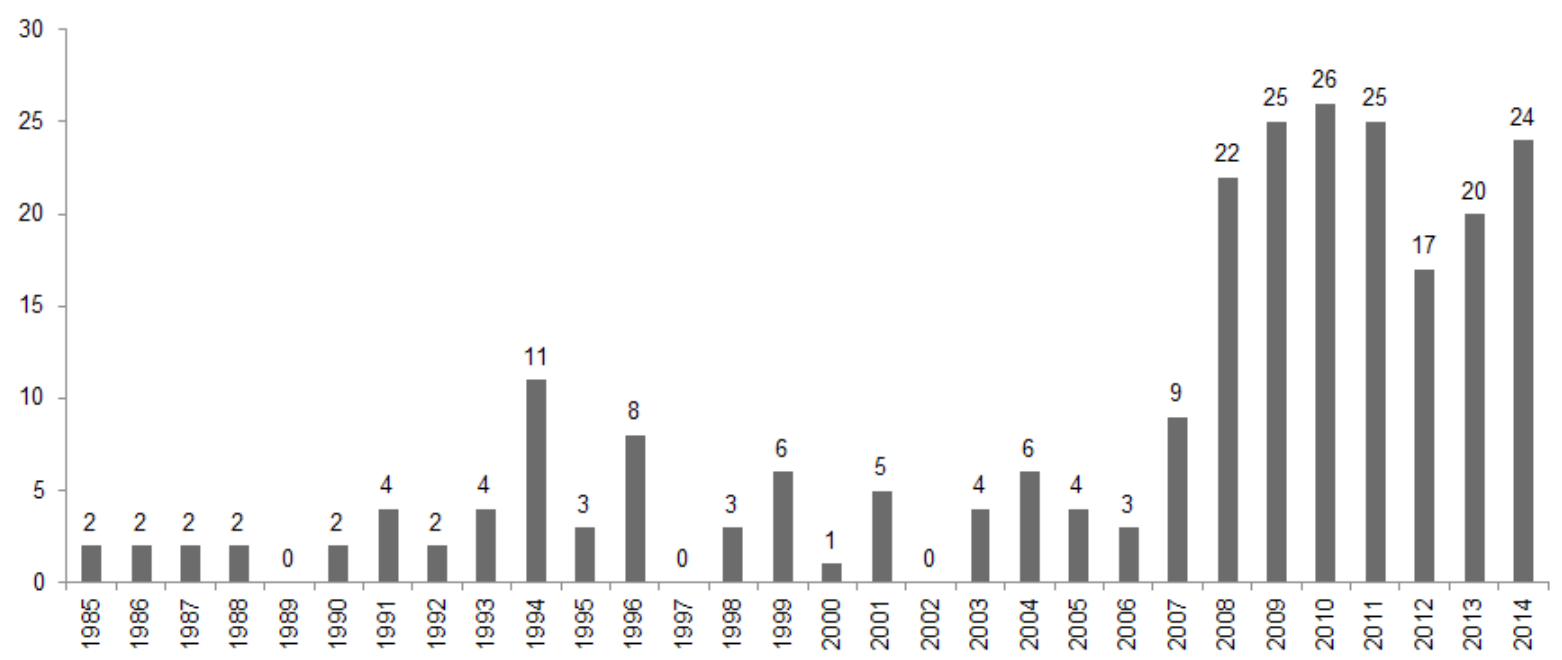

Figura 2. Evolução do tema

Fonte: dados da pesquisa.

As pesquisas de Lunkes et al. (2011) e Beuren e Hall (2014) corroboram de maneira similar os achados deste estudo nesta seção.

A Figura 3 visualiza os 26 periódicos internacionais identificados neste estudo. Os periódicos Accounting, Organizations and Society e Management Accounting Research foram os que se destacaram na produção acadêmica do tema "Contabilidade Gerencial" neste estudo, com 73 e 53 artigos publicados respectivamente. Estas revistas científicas, especialmente a Accounting, Organizations and Society, também são enfatizadas e colocadas em evidência nas pesquisas nacionais dos autores: Borba e Murcia (2006), Riccio, Mendonça Neto e Sakata (2007), Murcia e Borba (2008), Borba et al. (2009) e Beuren e Nascimento (2014). Com isso, percebe-se a acuidade desses periódicos para a difusão e disseminação do conhecimento científico do tema "Contabilidade Gerencial" em âmbito global. 


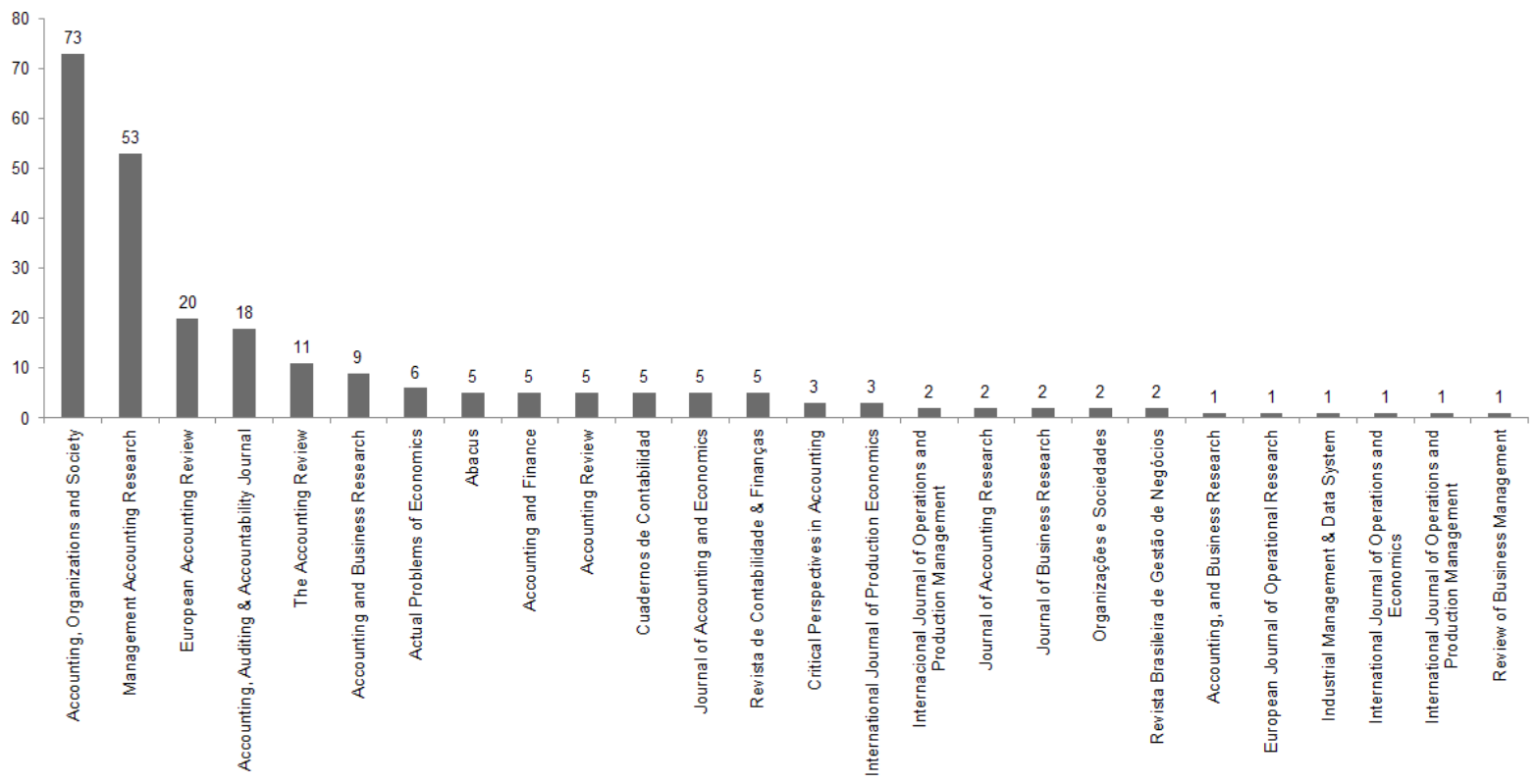

Figura 3. Periódicos

Fonte: dados da pesquisa.

As revistas European Accounting Review, Accounting, Auditing \& Accountability Journal e The Accounting Review também ficaram em evidência neste estudo, com 20, 18 e 11 artigos publicados sobre o assunto objeto de estudo desta pesquisa. Esses cinco periódicos, que ficaram em evidência nesta seção, equivalem a um montante de 175 artigos publicados sobre contabilidade gerencial de 1985 a 2014, perfazendo aproximadamente $72 \%$ do total dos 242 papers identificados e aferidos neste estudo. Essa informação remete à Lei de Bradford, que afere a produtividade dos periódicos científicos, permitindo, assim, constituir o núcleo de revistas sobre determinado tema (Ribeiro, 2014c; Ribeiro, Costa \& Ferreira, 2015).

Pode-se entender que o citado núcleo de revistas que evidenciam de maneira mais sistemática e robusta o tema "Contabilidade Gerencial" no âmbito internacional são: Accounting, Organizations and Society, Management Accounting Research, European Accounting Review, Accounting, Auditing \& Accountability Journal e The Accounting Review.

A Figura 4 evidência os 390 autores identificados neste estudo, colocando com maior realce os 15 com maior produção científica sobre o tema ora investigado. O pesquisador Lukka foi o mais profícuo nesse estudo, publicando nove artigos sobre o tema mapeado; em seguida, aparece o autor Modell, com sete publicações; com seis, está o acadêmico Gerdin; com quatro divulgações estão os articulistas Abernethy, Malmi e Frezatti; e com três têm-se os pesquisadores Jones, Chenhall, Bouwens, Hartmann, Davila, Järvinen, Naranjo-Gil, Englund e Maas.

Em suma, 15 acadêmicos publicaram de três a nove artigos sobre o tema "Contabilidade Gerencial"; 45 autores publicaram dois artigos; e a grande maioria, ou seja, 330 pesquisadores, divulgaram uma publicação cada. Tais dados e informações remetem à Lei de Lotka que mensura a quantidade de autores (Da Silva \& Beuren, 2015) que publicam n pesquisas em um determinado campo do conhecimento (Tavares Araújo \& Castro Silva, 2010). Ou seja, poucos pesquisadores publicam muito e muitos pesquisadores publicam pouco (Souza \& Ribeiro, 2013), o que pode ser visualizado na Figura 4. 


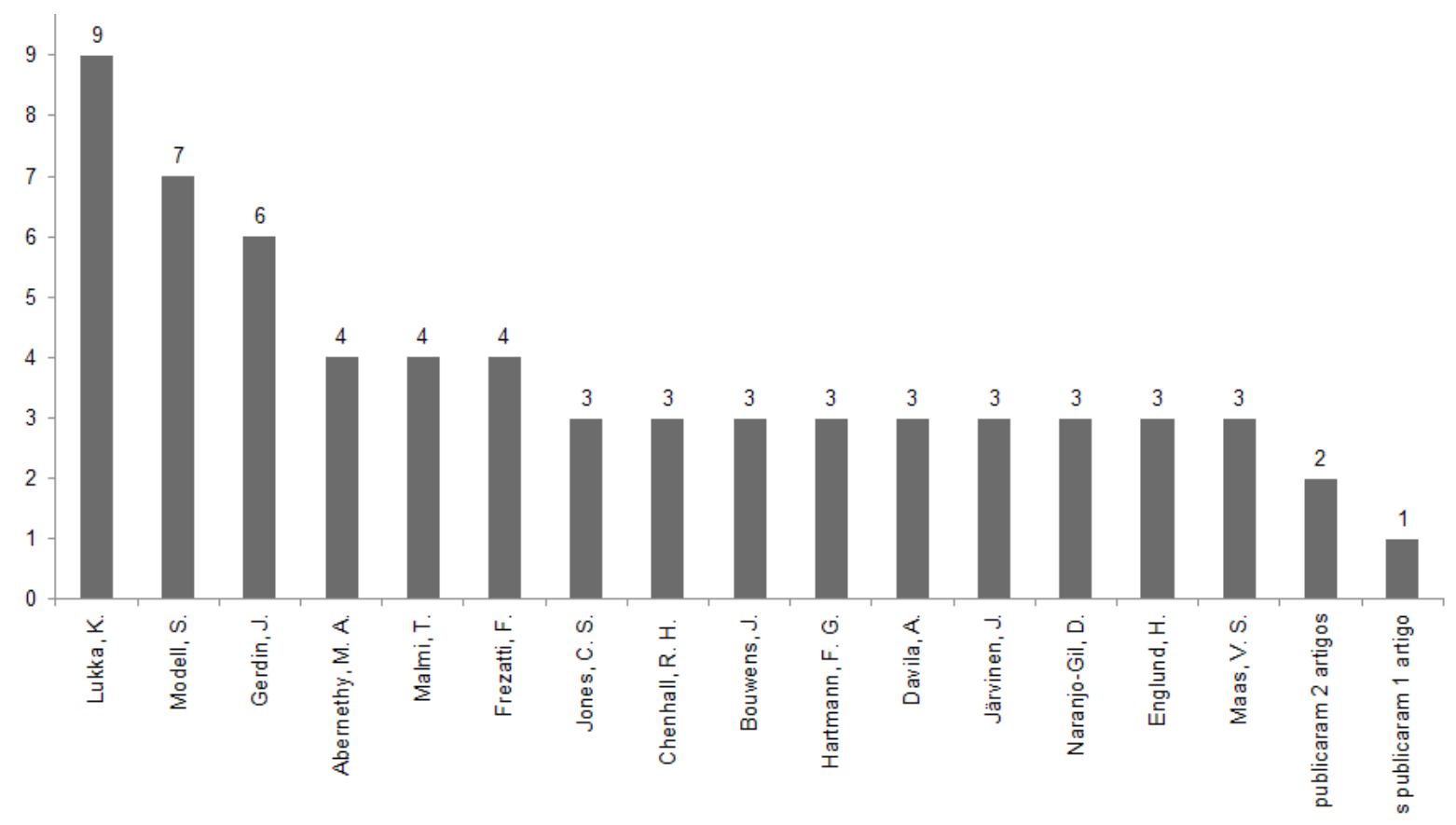

Figura 4. Autores

Fonte: dados da pesquisa.

A Figura 5 visualiza a rede de coautoria dos 390 autores identificados nesta pesquisa. A rede de coautoria deste estudo apresenta-se com uma densidade de 0,0045 , o que representa $0,45 \%$ das interações entre os autores da citada rede social, estando, assim, muito aquém da ideal (Mendes-da-Silva, Onusic \& Giglio, 2013).

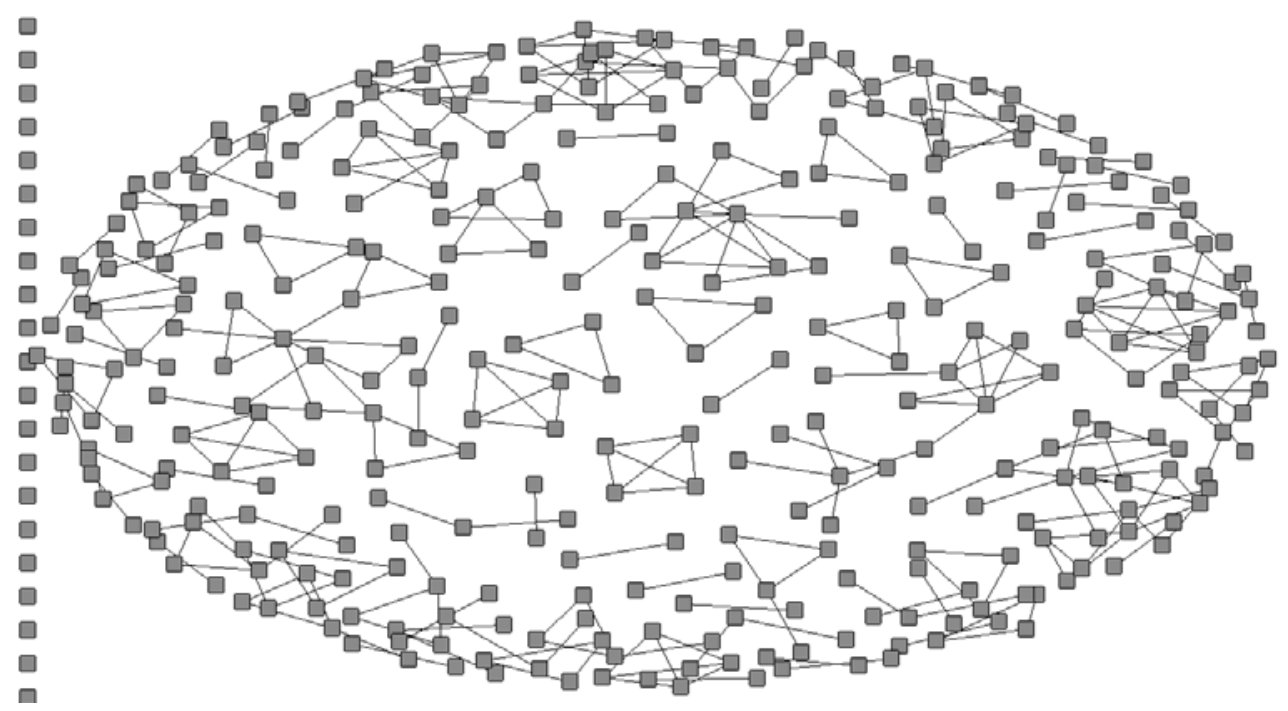

Figura 5. Rede de coautoria

Fonte: dados da pesquisa. 
Em outras palavras, 99,55\% das interações ativas possíveis existentes nesse grupo de atores ainda não são efetivamente realizadas, o que compromete substancialmente o potencial de difusão da informação entre esses atores da rede (Guimarães et al., 2009), o que equivale a uma rede social que se caracteriza por laços fracos, impactando na centralidade de grau (Mendes-da-Silva, Onusic \& Giglio, 2013).

A Figura 6 contempla a mesma rede de coautoria vista na Figura 5, porém colocando em ênfase a centralidade de grau da citada rede social.

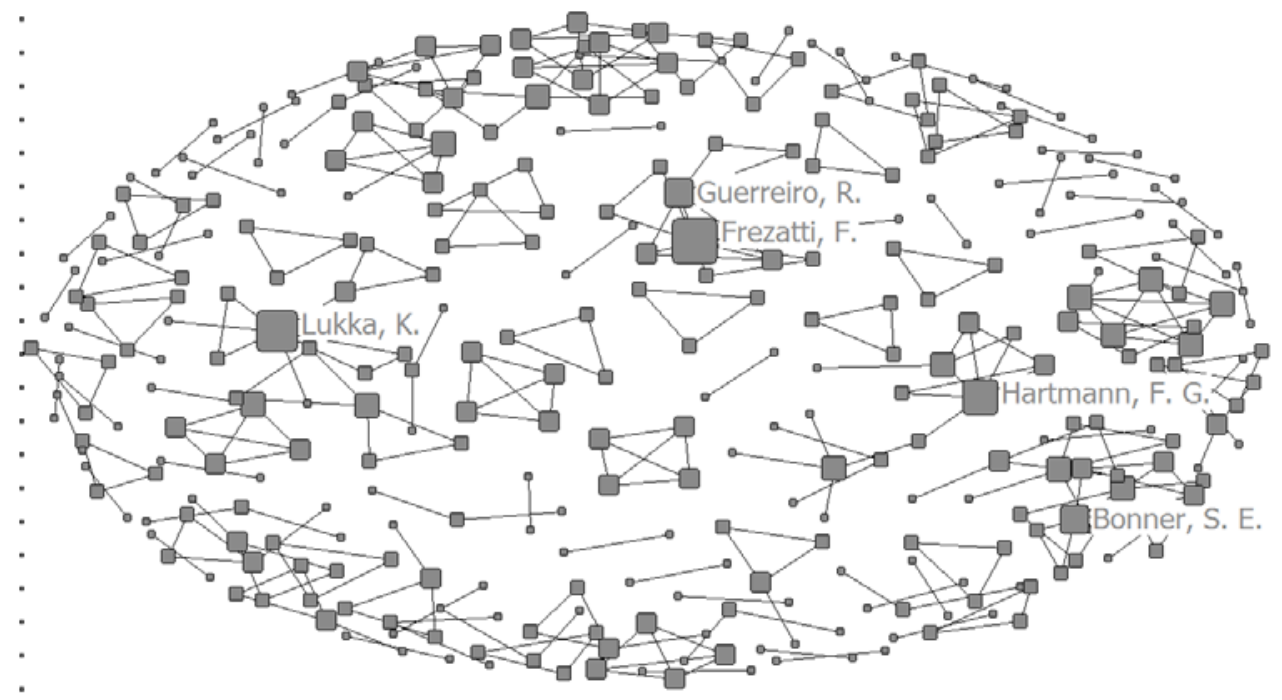

Figura 6. Rede de coautoria (degree)

Fonte: dados da pesquisa.

Os autores Frezatti, Lukka, Hartmann, Bonner e Guerreiro são os mais centrais, no que se refere ao degree neste estudo. Sendo que, desses, três aparecem também como os mais profícuos na produção do tema "Contabilidade Gerencial", são eles: Frezatti, Lukka e Hartmann.

Também ao entender que a centralidade de grau foca no número de laços adjacentes de um ator em relação aos outros em uma rede (Wasserman \& Faust, 1994), contribuindo para melhor mensurar sua importância posicional nessa rede social (Rossoni \& Guarido Filho, 2009), pode-se dizer, com isso, que os pesquisadores Frezatti, Lukka, Hartmann, Bonner e Guerreiro são os mais importantes na citada rede, contribuindo, assim, para a difusão e disseminação de ideias, informações e conhecimentos sobre o assunto contabilidade gerencial, no panorama da literatura acadêmica internacional. 
A Figura 7 identifica rede de coautoria visualizada na Figura 5, contudo, contemplando a centralidade de intermediação.

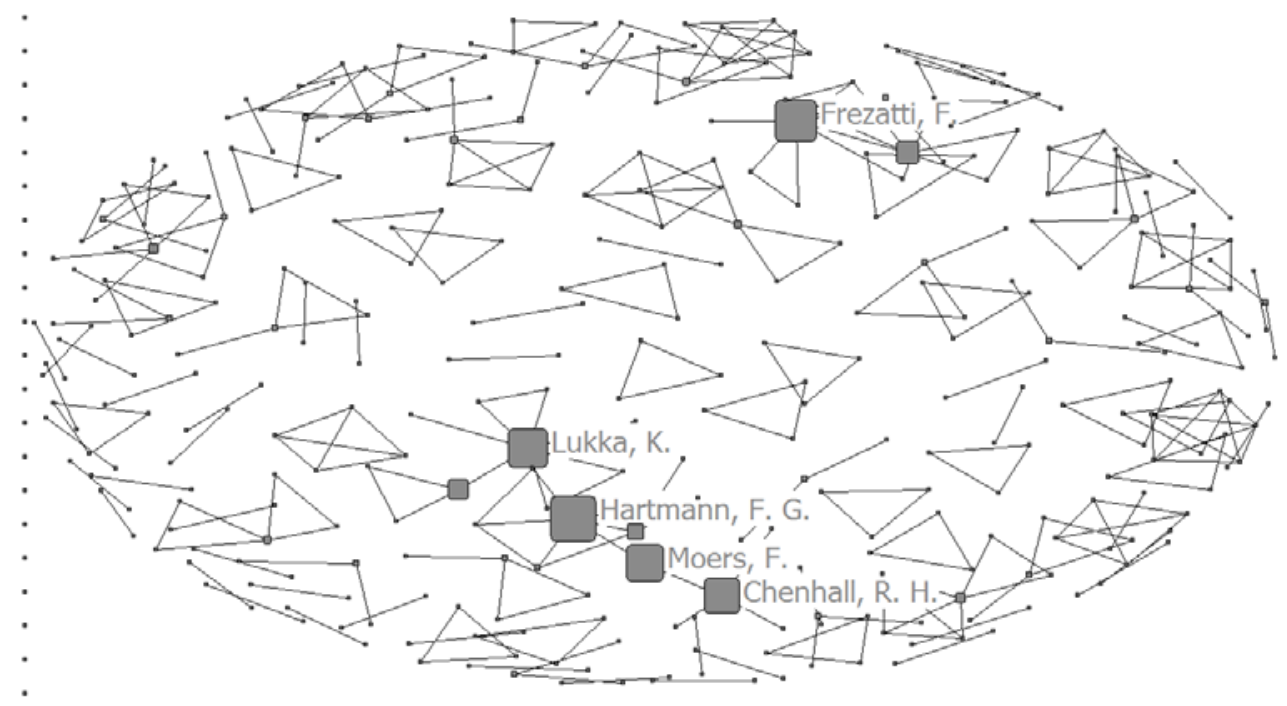

Figura 7. Rede de coautoria (betweenness)

Fonte: dados da pesquisa.

Compreendendo que a centralidade de intermediação vislumbra os autores que ostentam uma posição de intermediador em uma rede social (Ribeiro, 2015), na rede visualizada na Figura 7, estes autores são: Hartmann, Frezatti, Lukka, Chenhall e Moers. Destes, quatro aparecem como os mais profícuos: Hartmann, Frezatti, Lukka e Chenhall; e destes, três também se destacam na centralidade de grau, que são: Hartmann, Frezatti e Lukka. Sendo assim, estes, são considerados os mais essenciais e centrais nas redes de coautoria concebidas neste estudo.

Pode-se dizer e entender que os acadêmicos que ficaram em realce nesta seção são vistos e considerados como uma espécie de ponte para a concretização da relação com os outros acadêmicos da mesma rede (Ribeiro, 2015), isto é, são os maiores responsáveis pela troca de informação na citada rede de coautoria (Ribeiro, Cirani \& Freitas, 2013). Salienta-se que o papel de intermediação admitido por esses pesquisadores na aludida rede social permitem e colaboram para a troca de ideias, informações e conhecimento entre grupos distintos (Rossoni \& Guarido Filho, 2009).

A Figura 8 traz as 133 IES identificadas neste estudo, colocando em foco as 15 mais bem colocadas, em decorrência de suas respectivas produções científicas sobre o tema ora analisado.

A University of Turku foi a que se destacou nesta seção, com 12 artigos publicados; em seguida, com oito, estão as IES, Orebro University e University of Manchester; a University of London divulgou sete artigos; com cinco publicações, aparecem as universidades Aalto University, Monash University, Universidade de São Paulo, University of Melbourne, University of Pennsylvania e University of South Australia; e com quatro papers evidenciados têm-se as instituições de ensino Cardiff University, Erasmus University Rotterdam, Griffith University, National Academy Management e University of New South Wales. Dessas, cinco universidades são oriundas da Austrália, sendo que esse país está entre os três que se destacaram na publicação de artigos sobre a temática "Contabilidade Gerencial" (Figura 9). 


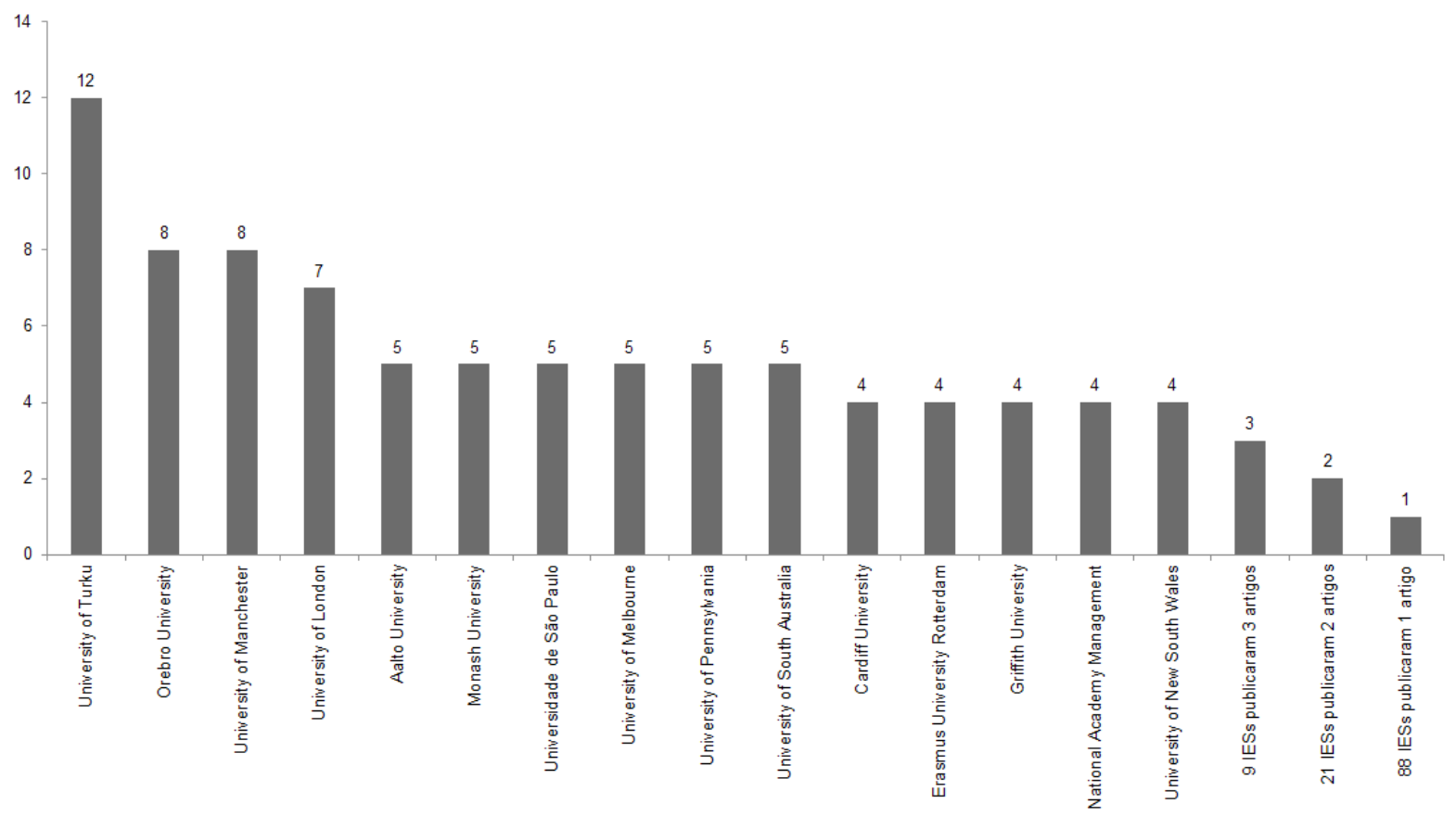

Figura 8. IESS

Fonte: dados da pesquisa.

A Universidade de São Paulo é colocada em evidência, mostrando assim, sua importância no contexto nacional no que tange à produção cientifica do tema "Contabilidade Gerencial" na literatura científica brasileira. Cruz et al. (2010) e Oliveira e Boente (2012), em suas respectivas pesquisas corroboram a afirmação de maneira geral.

A Figura 9 evidencia os 26 países identificados neste estudo. Os Estados Unidos da América (EUA), Inglaterra e Austrália se destacaram na produção científica do tema "Contabilidade Gerencial", com 41, 37 e 33 artigos publicados, respectivamente. Tal achado dá a entender que esses países são os norteadores centrais e influentes na produção acadêmica da citada temática. Outros estudos bibliométricos, que focaram a produção científica de outros assuntos, também constataram a assiduidade e a importância dessas nações na difusão e socialização do conhecimento desses assuntos, foram eles: Ribeiro (2014a), Ribeiro (2014b) e Ribeiro, Costa e Ferreira (2015). 


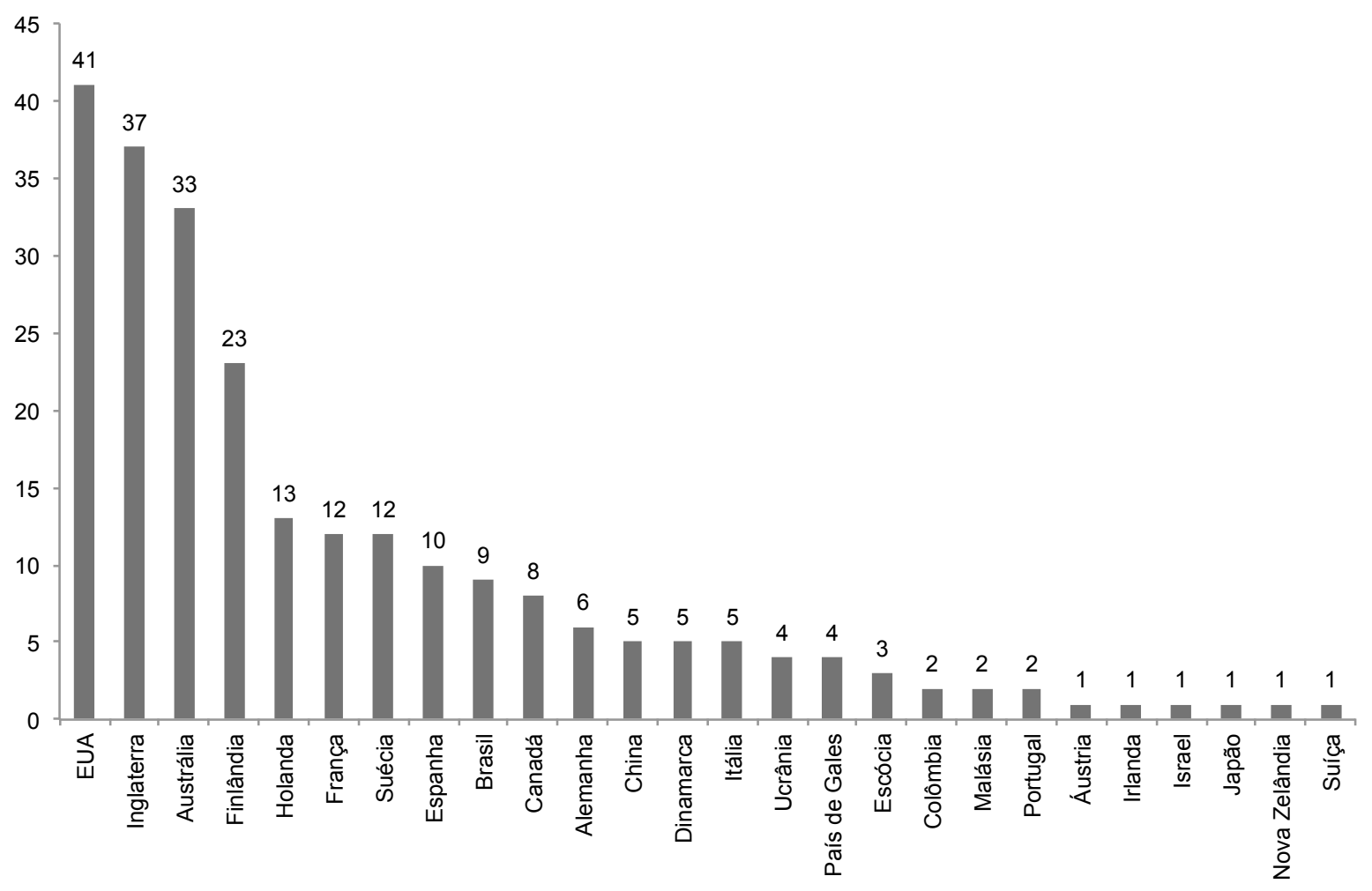

Figura 9. Países

Fonte: dados da pesquisa.

O Brasil surge entre os 10 países com maior produção acadêmica sobre o tema objeto de estudo, com nove publicações, sendo que essas 10 divulgações são oriundas da USP, que nesta pesquisa publicou cinco papers sobre o mencionado tema. Tal achado denota que, mesmo estando incipiente a produção acadêmica nacional, no contexto internacional sobre o assunto "Contabilidade Gerencial", o Brasil se destaca, entre as nações que mais publicaram. Isso demonstra a importância e a maturidade que o tema tem no contexto da literatura acadêmica nacional (Lunkes et al., 2011), podendo a posteriori tal maturidade ser alargada em médio ou longo prazo, também, no cenário acadêmico internacional.

Entende-se que as citações são importantes para a construção do conhecimento científico (Silveira \& Bazi, 2010). Em vista disso, o Quadro 2 exalta os 10 artigos mais citados durante a temporalidade de 30 anos sobre o assunto "Contabilidade Gerencial" no contexto internacional. 
Quadro 2

10 artigos mais citados

10 Artigos mais Citados

Feltham, G. A., \& Xie, J. (1994). Performance measure congruity and diversity in multi-task principal/agent relations. The Accounting Review, 429-453.

Luft, J., \& Shields, M. D. (2003). Mapping management accounting: graphics and guidelines for theory-consistent empirical research. Accounting, Organizations and Society, 28(2), 169-249.

Chenhall, R. H., \& Morris, D. (1986). The impact of structure, environment, and interdependence on the perceived usefulness of management accounting systems. The Accounting Review, 16-35.

Chenhall, R. H., \& Langfield-Smith, K. (1998). The relationship between strategic priorities, management techniques and management accounting: an empirical investigation using a systems approach. Accounting, Organizations and Society, 23(3), 243-264.

Briers, M., \& Chua, W. F. (2001). The role of actor-networks and boundary objects in management accounting change: a field study of an implementation of activity-based costing. Accounting, Organizations and Society, 26(3), 237-269.

Malmi, T., \& Brown, D. A. (2008). Management control systems as a package-Opportunities, challenges and research directions. Management Accounting Research, 19(4), 287-300.

Abernethy, M. A., \& Brownell, P. (1999). The role of budgets in organizations facing strategic change: an exploratory study. Accounting, Organizations and Society, 24(3), 189

Abernethy, M. A., \& Lillis, A. M. (1995). The impact of manufacturing flexibility on management control system design. Accounting, Organizations and Society,20(4), 241-258.

Wruck, K. H., \& Jensen, M. C. (1994). Science, specific knowledge, and total quality management. Journal of Accounting and Economics, 18(3), 247-287.

Baines, A., \& Langfield-Smith, K. (2003). Antecedents to management accounting change: a structural equation approach. Accounting, Organizations and Society,28(7), 675-698.

Fonte: dados da pesquisa.

Compreende-se que a análise das citações admite constatar o fluxo divulgado e a evolução de um determinado estudo ao longo de uma temporalidade, e que pode servir, portanto, como fonte para se mensurar a influência direta e/ou indireta de uma determinada pesquisa específica de um grupo de estudo e/ ou de uma IES de acadêmicos, ou ainda de periódicos científicos (Caldas \& Tinoco, 2004).

Observou-se que, dos 10 artigos mais citados, seis são do periódico Accounting, Organizations and Society, que também neste estudo foi destaque como a revista que mais publicou estudos sobre o tema analisado. Ainda sobre os 10 papers mais citados, quatro são do século XXI, ou seja, da década 2000. O autor Chenhall teve duas obras entre as mais citadas. Ressalta-se também que o citado pesquisador é destaque também nesta pesquisa como um dos mais profícuos e é colocado em evidencia como um dos acadêmicos com maior centralidade de intermediação.

A Figura 10 demonstra os 50 temas sobre contabilidade gerencial identificados neste estudo. sendo Educação, ensino e pesquisa contábil o tema mais abordado, com 33 artigos publicados salvo dizer que o assunto abordou temáticas e/ou métodos de pesquisas que versavam sobre educação e ensino contábil, buscando assim compreender a evolução da área contábil e/ou sua história no contexto global. E em relação aos métodos, alguns estudos enfocaram a análise, investigação, mapeamento e/ou exploração de diversos assuntos voltados ou ligados direta ou indiretamente à contabilidade gerencial, mediante pesquisas de suas respectivas produções acadêmicas.

O assunto "Gestão de Custos" ficou em segundo lugar com 23 papers divulgados em 30 anos de pesquisas sobre o tema central deste estudo, ou seja, a contabilidade gerencial. É importante evidenciar que a gestão de custos é assunto intrínseco à temática "Contabilidade Gerencial" (Briers \& Chua, 2001; Carmo et al., 2014), sendo importante para os gestores nas tomadas de decisão (Küpper, 2009). Realça-se ainda que o custeio $\mathrm{ABC}$ ficou em evidência neste estudo. 


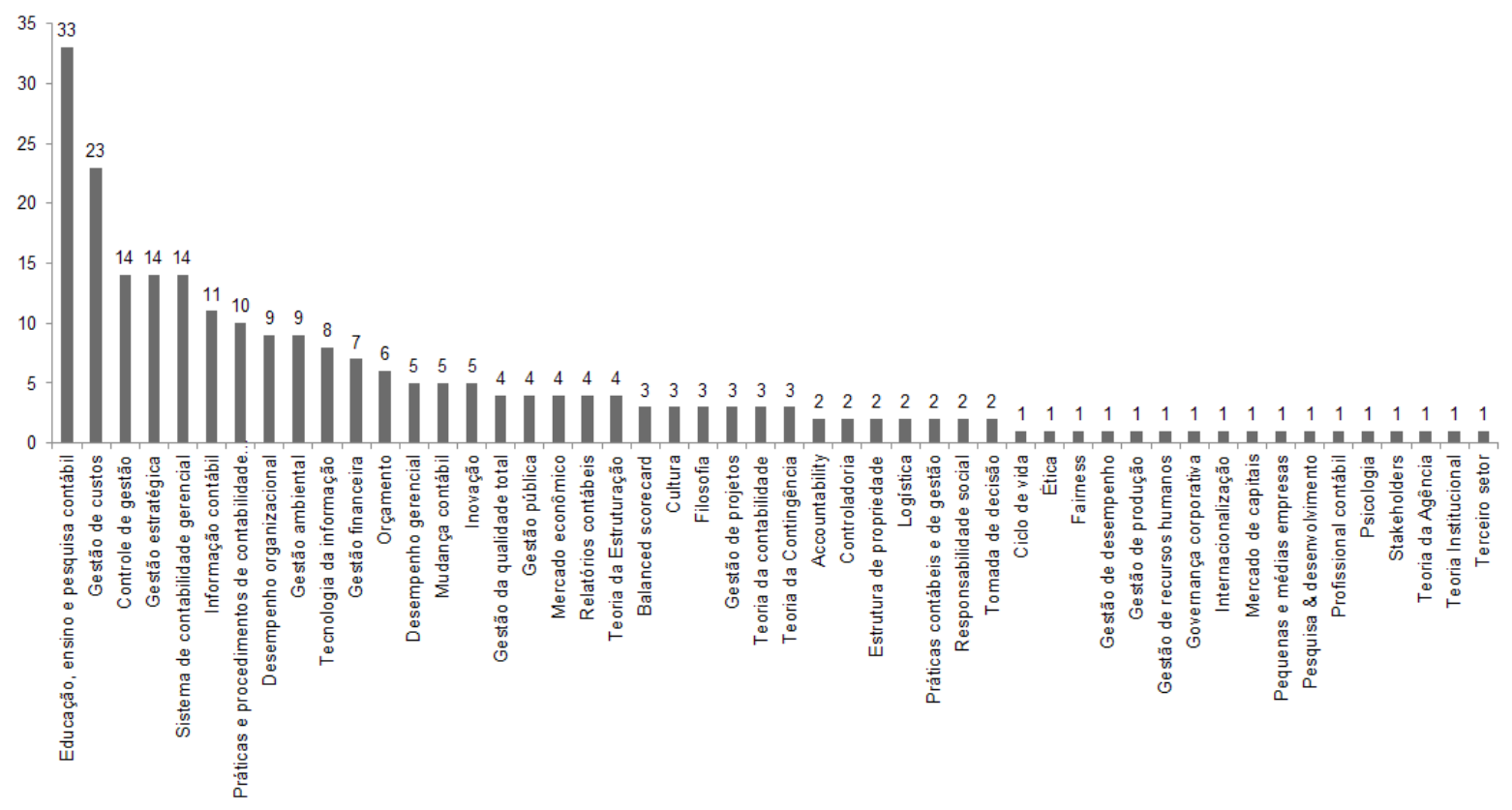

Figura 10. Temas abordados

Fonte: dados da pesquisa.

Os temas "Controle de Gestão", "Gestão Estratégica" e "Sistema de Contabilidade Gerencial" também ficaram em destaque nesta pesquisa, ao serem divulgados, cada um, 14 vezes. Diante disso, ressalta-se que o destaque desses três assuntos é em virtude da importância dos SCG, pois, eles acumulam procedimentos incorporados na contabilidade gerencial, como orçamento e custos de produção, ao mesmo tempo em que compreendem processos sistemáticos usados para alcançar os objetivos do negócio da empresa, incididos de outros campos do conhecimento. De maneira geral, os SCG, compõem-se de controles de gestão, que possibilitam e evidenciam informações contábeis de rotinas e processos utilizados por gestores para facilitar as tomadas de decisões estratégicas de gestão (Beuren \& Oro, 2014).

Em suma, 50 temas foram identificados neste estudo, sendo que os cinco primeiros equivalem a aproximadamente $40 \%$ do montante dos 242 artigos publicados sobre a contabilidade gerencial. 15 temas foram divulgados de quatro a 11 vezes; 13 assuntos foram publicados de duas a três vezes; e 17 temáticas foram publicadas somente uma vez cada.

Por ser esse achado, uma ocasião de fomento, difusão e disseminação, ainda mais sobre o tema "Contabilidade Gerencial" na literatura científica internacional, esses assuntos que se vinculam direta ou indiretamente a esse tema só foram publicados apenas uma vez em 30 anos de estudos, significando que eles ainda são embrionários no contexto internacional, proporcionando e contribuindo, assim, em uma oportunidade de alargar seus respectivos conhecimentos no âmbito acadêmico global, com impacto direto na otimização, evidenciação e socialização do tema principal deste estudo. 


\section{Considerações finais}

O objetivo deste estudo foi analisar o comportamento e as particularidades da produção acadêmica do tema Contabilidade Gerencial divulgada no ISI Web of Science Core Collection de 1985 a 2014.

A partir de 2007, observou-se uma evolução do assunto "Contabilidade Gerencial". O periódico Accounting, Organizations and Society foi o que se destacou na divulgação da publicação do tema investigado. Lukka foi o autor mais profícuo; a IES que ficou em evidência foi a University of Turku; os EUA foram o país que ficou em foco neste estudo; as redes de coautoria tiveram baixa densidade e alta centralidade de grau e de intermediação; e os assuntos que ficaram em ênfase foram: Educação, Ensino e Pesquisa Contábil, Gestão de Custos, Controle de Gestão, Gestão Estratégica e Sistema de Contabilidade Gerencial.

O tema "Contabilidade Gerencial" como observado neste estudo, já se encontra em uma fase madura e legitimada no contexto acadêmico internacional. Tal afirmação pode ser confirmada mediante os temas identificados e abordados neste trabalho, contemplando assim uma diversidade de assuntos que se atrelam e interagem de maneira sistêmica, recorrente e com grande difusão na contabilidade gerencial, ajudando, por si sós, a aperfeiçoarem e a difundirem de maneira mais robusta e alargada o citado tema, não somente no âmbito acadêmico global, mas também no cenário empresarial.

De certa forma, mesmo verificando a heterogeneidade dos temas abordados neste estudo, ainda há a possibilidade de melhor desenvolve-los, especialmente os temas menos divulgados, pegando por base a temporalidade trabalhada neste estudo. E com isso, aperfeiçoando-os, impactaria uma tendência de maior desenvolvimento do tema "Contabilidade Gerencial", possibilitando o surgimento de novos grupos de estudos, novas pesquisas, novos modelos, novos insights, para agregar isso valor à pesquisa em contabilidade gerencial, influenciando de maneira aflorada no crescimento do campo de saber da área contábil.

Essas novas pesquisas que surgem, desenvolvendo temas que se relacionam com a contabilidade gerencial, em especial, os assuntos emergentes e os embrionários contribuiriam para nortear, alargar e conceber novos procedimentos, processos e/ou métodos de trabalho no campo empresarial, colaborando para otimizar e concretizar ainda mais a contabilidade gerencial como o tema preponderante e ímpar que é nos processos decisórios e tomadas de decisões nas organizações.

Não se pode entender uma determinada temática se antes não compreendê-la. Este estudo, por meio dos indicadores bibliométricos e sociométricos, possibilitou e contribuiu para tal, trazendo a tona dados e informações novas e contemporâneas sobre as nuances alargadas e ricas que norteiam e embasam o tema "Contabilidade Gerencial" no campo acadêmico, como, por exemplo, os estudos mais citados, as redes sociais dos atores (autores e IES), os autores mais profícuos, as IES mais produtivas e os países que se destacam na produção deste tema no mundo.

Este estudo também contribuiu para evidenciar dados e informações contemporâneas sobre o tema "Contabilidade Gerencial", no âmbito internacional, cooperando para ajudar a difundir, evidenciar e disseminar o conhecimento sobre o tema no âmbito literário acadêmico internacional e nacional, proporcionando melhor entendimento e compreensão por parte dos pesquisadores já legitimados da área e por aqueles acadêmicos que querem e desejam melhor juízo e abrangência sobre o pesquisado.

Conclui-se neste estudo que esforços como este, isto é, de analisar a produção científica do tema "Contabilidade Gerencial" contribuem também para o maior discernimento e acréscimo, não somente da temática em si, mas também dos temas que lhes são inerentes e relacionados de alguma forma, e que foram evidenciados na Figura 10 deste estudo, contribuindo para o desenvolvimento de novas pesquisas correlatas e/ou estudos que usem técnicas e métodos similares e/ou diferentes, mas que de certa maneira, robusteçam a produção científica da abordagem da contabilidade gerencial na literatura científica internacional. 
Este estudo limitou-se em pesquisar as publicações divulgadas no ISI Web of Science Core Collection de 1985 a 2014. Com isso, sugere-se para estudos futuros uma otimização e/ou aperfeiçoamento deste estudo, alargando a busca por artigos sobre contabilidade gerencial em outras bases de dados, como, por exemplo o Scopus. Sugere-se também, para estudos futuros, um maior realce das técnicas de análise de rede social, buscando também entender as ligações de outros atores, como, por exemplo, as IES, países e citações. Outra sugestão para futuras pesquisas é melhor entender e compreender os 50 temas evidenciados neste estudo, enfocando de maneira mais analítica todos eles ou, pelo menos, os mais destacados, por meio de uma análise de conteúdo.

\section{Referências}

Bar-Ilan, J. (2008). Which h-index? - A comparison of WoS, Scopus and Google Scholar. Scientometrics, 74(2), pp. 257-271. doi: 10.1007/s11192-008-0216-y.

Barros, L. P. de S., Schekaiban, N. F. C., Gomes, J. S., \& Feliu, V. R. (2008). Estudo comparativo na área de contabilidade gerencial entre Brasil, México e Espanha. Revista Iberoamericana de Contabilidad de Gestión, (12), pp. 13-36.

Beuren, I. M., \& Nascimento, S. do. (2014). Perfil dos artigos de contabilidade gerencial da accounting, organizations and society publicados de 2005 a 2009. Revista de Administração e Contabilidade da Unisinos, 11(4), pp. 332-346. doi: 10.4013/base.2014.114.05.

Beuren, I. M., \& Oro, I. M. (2014). Relação entre estratégia de diferenciação e inovação, e sistemas de controle gerencial. Revista de Administração Contemporânea, 18(3), pp. 285-310. doi: 10.1590/19827849rac20141394.

Beuren, I. M., \& Hall, R. J. (2014). Perfil dos artigos que utilizaram a estratégia do estudo de caso em pesquisas sobre a prática da contabilidade gerencial. Revista de Administração, Contabilidade e Economia, 13(1), pp. 219-248.

Beuren, I. M., \& Macohon, E. (2011). Institucionalização de hábitos e rotinas na contabilidade gerencial à luz da teoria da contingência: Um estudo em indústrias de móveis em São Bento do Sul. Revista Portuguesa e Brasileira de Gestão, 10(1-2), pp. 78-91.

Beuren, I. M., \& Erfurth, A. E. (2010). Pesquisa em contabilidade gerencial com base no futuro realizada no Brasil. Contabilidade, Gestão e Governança, 13(1), pp. 44-58.

Borba, J. A., Murcia, F. D. R., Rover, S., \& Souza, F. C. de (2009). Paradigma atual da ciência contábil: percepção de docentes de universidades norte-americanas em relação à pesquisa em contabilidade. Revista de Educação e Pesquisa em Contabilidade, 3(1), pp. 65-86. doi: 10.17524/repec.v3i1.41.

Borba, J. A., \& Murcia, F. D. R. (2006). Opportunities for research and publication in accounting: a preliminary study on academic journals published in english and available at the CAPES's basis. Brazilian Business Review, 3(1), pp. 86-101. doi: 10.15728/bbr.2006.3.1.7.

Bornmann, L. (2010). Mimicry in science? Scientometrics, 86(1), pp.173-177. doi: 10.1007/s11192-0100222-8.

Briers, M., \& Chua, W. F. (2001). The role of actor-networks and boundary objects in management accounting change: a field study of an implementation of activity-based costing. Accounting, Organizations and Society, 26(3), pp. 237-269. doi: 10.1016/S0361-3682(00)00029-5.

Brizolla, M. M. B., Chiarello, T. C., \& Lavarda, C. E. F. (2014). Abordagem a respeito da controladoria e contabilidade gerencial: um estudo das redes sociais publicado em periódicos internacionais. Revista de Gestão e Contabilidade da UFPI, 1(1), pp. 119-140. 
Caldas, M. P., \& Tinoco, T. (2004). Pesquisa em gestão de recursos humanos nos anos 1990: um estudo bibliométrico. Revista de Administração de Empresas, 44(3), pp. 100-114. doi: 10.1590/S003475902004000300008 .

Carmo, C. R. S. do, Xavier, L. V., Pereira, V. S., \& Martins, V. F. (2014). O perfil das pesquisas sobre contabilidade gerencial e contabilidade de custos na pós-graduação stricto sensu da fea-usp a partir de um recorte temporal de 1998 a 2011. Revista de Administração e Contabilidade da FAT, 6(1), pp. 70-87.

Carvalho, K. L. de, Saraiva Junior, A. F., Frezatti, F., \& Costa, R. P. da. (2010). A contribuição das teorias do ciclo de vida organizacional para a pesquisa em contabilidade gerencial. Revista de Administração Mackenzie, 11(4), pp. 98-130. doi: 10.1590/S1678-69712010000400005.

Chenhall, R. H., \& Morris, D. (1986). The impact of structure, environment, and interdependence on the perceived usefulness of management accounting systems. The Accounting Review, 61(1), pp. 16-35.

Colauto, R. D., \& Almeida, V. E. de. (2013). Teoria institucional associada à contabilidade gerencial: estudo bibliométrico 2009-2012. Revista Ciências Sociais em Perspectiva, 12(22), pp. 1-21.

Cronin, B. (2001). Bibliometrics and beyond: some thoughts on web-based citation analysis. Journal of Information Science, 27(1), pp. 1-7. doi: 10.1177/016555150102700101.

Cruz, A. P. C. da, Espejo, M. M. dos S. B., Gassner, F. P., \& Walter, S. A.. (2010). Uma análise do desenvolvimento do campo de pesquisa em contabilidade gerencial sob a perspectiva colaborativa mapeada em redes sociais. Revista Contabilidade Vista \& Revista, 21(2), pp. 95-120.

Cruz, C., \& Ribeiro, U. (2003). Metodologia científica: teoria e prática. Rio de Janeiro: Axcel Books.

Cunha, P. R. da, Santos, V. dos, \& Beuren, I. M. (2015). Artigos de periódicos internacionais que relacionam teoria institucional com contabilidade gerencial. Revista Perspectivas Contemporâneas, 10(2), pp. 01-23.

Da Silva, M. Z., \& Beuren, I. M. (2015). Contabilidade gerencial em hospitais: análise bibliométrica de artigos publicados no período 1950 a 2011. Alcance, 22(1), pp.80-104. doi: alcance.v22n1.p80-104.

Daim, T. U., Rueda, G., Martin, H., \& Gerdsri, P. (2006). Forecasting emerging technologies: Use of bibliometrics and patent analysis. Technological Forecasting and Social Change, 73(8), pp. 981-1012. doi: 10.1016/j.techfore.2006.04.004.

El-Maamiry, A. A., \& Abid Ghauri, M. (2013). Measuring Information Quality: Concerns on the Use of Bibliometric Studies. International Journal of Information Dissemination \& Technology, 3(4), pp. 274-278.

Falagas, M. E., Pitsouni, E. I., Malietzis, G. A., \& Pappas, G. (2008). Comparison of PubMed, Scopus, web of science, and Google scholar: strengths and weaknesses. The Faseb Journal, 22(2), pp 338-342. doi: 10.1096/fj.07-9492LSF.

Galaskiewicz, J., \& Wasserman, S. (1994). Advances in social network analysis: Research in the social and behavioral sciences. Sage Publications.

Glänzel, W., Debackere, K., Thijs, B., \& Schubert, A. (2006). A concise review on the role of author self-citations in information science, bibliometrics and science policy. Scientometrics, 67(2), pp. $263-$ 277. doi: 10.1007/s11192-006-0098-9.

Guerreiro, R., Cornachione Júnior, E. B., \& Soutes, D. O. (2011). Empresas que se destacam pela qualidade das informações a seus usuários externos também se destacam pela utilização de artefatos modernos de contabilidade gerencial? Revista Contabilidade \& Finanças, 22(55), pp. 88-113. doi: 10.1590/S1519-70772011000100006. 
Guerreiro, R., Frezatti, F., Lopes, A. B., \& Pereira, C. A. (2005). O entendimento da contabilidade gerencial sob a ótica da teoria institucional. Organizações \& Sociedade, 12(35), pp. 91-106. doi: 10.1590/ S1984-92302005000400005.

Guimarães, T. de A., Gomes, A. de O., Odelius, C. C., Zancan, C., \& Corradi, A. A. (2009). A rede de programas de pós-graduação em administração no Brasil: análise de relações acadêmicas e atributos de programas. Revista de Administração Contemporânea, 13(4), pp. 564-582. doi: 10.1590/S141565552009000400004 .

Guz, A. N., \& Rushchitsky, J. J. (2009). Scopus: A system for the evaluation of scientific journals. International Applied Mechanics, 45(4), pp. 351-362. doi: 10.1007/s10778-009-0189-4.

Hayashi, M. C. P. I., Hayashi, C. R. M., Silva, A. M., \& Maycke, Y. de. (2007). Um estudo bibliométrico da produção científica sobre a educação jesuítica no Brasil colonial. Biblios: Revista Electrónica de Bibliotecología, Archivología y Museología, 8(27), pp. 1-18.

Hid, D. S., Nascimento, C., \& Oliveira, D. A. (2012). Análise das publicações internacionais relacionadas ao desenvolvimento sustentável na área de administração: uma análise bibliométrica da produção científica. Administração: Ensino e Pesquisa, 13(4), pp. 653-671. doi: 10.13058/raep.2012.v13n4.77.

Hoffman, D. L., \& Holbrook, M. B. (1993). The intellectual structure of consumer research: a bibliometric study of author cocitations in the first 15 years of the journal of consumer research. Journal of Consumer Research, 19(4), pp. 505-517. doi: 10.1086/209319.

Hopp, J. C., \& Leite, H. D. P. (1988). O crepúsculo do lucro contábil. Revista de Administração de Empresas, 28(4), pp. 55-63. doi: 10.1590/S0034-75901988000400007.

Kremer, A., Da Luz, M. B. L., Suave, R., \& Lunkes, R. J. (2014). Pesquisa científica em contabilidade gerencial: um estudo em periódicos de negócios. Revista de Contabilidade da UFBA, 8(1), pp. 54-69.

Küpper, H. U. (2009). Investment-based cost accounting as a fundamental basis of decision-oriented management accounting. Abacus, 45(2), pp. 249-274. doi: 10.1111/j.1467-6281.2009.00284.x.

Luft, J., \& Shields, M. D. (2003). Mapping management accounting: graphics and guidelines for theory-consistent empirical research. Accounting, Organizations and Society, 28(2), pp. 169-249. doi: 10.1016/S0361-3682(02)00026-0.

Lunkes, R. J., Gasparetto, V., Schnorrenberger, D., \& Rosa, F. S. (2014). Estudo descritivo sobre o desenvolvimento da contabilidade gerencial no Brasil sob a perspectiva da legitimidade. Advances in Scientific and Applied Accounting, 7(1), pp. 97-121. doi: 10.14392/asaa.2014070104.

Lunkes, R. J., Feliu, V. R., Borba, A. J., Rosa, F. S. (2012). Análise quantitativa da produção e da formação de doutores em contabilidade gerencial: um estudo no cenário espanhol. Revista Universo Contábil, 8(2), pp. 118-133. doi: 10.4270/ruc.2012216.

Lunkes, R. J., Feliu, V. M. R., \& Rosa, F. S. da. (2012). Pesquisa científica em contabilidade gerencial: estudo comparativo entre Espanha e Brasil. Contaduría y Administración, 57(2), pp. 159-184.

Lunkes, R. J., Rosa, F.S., Gasparetto, V. \& Baldoino, E. (2011). Análise da produção científica e formação de doutores em contabilidade gerencial: um estudo no cenário brasileiro. Advances in Scientific and Applied Accounting, 4(3), pp. 361-378.

Mendes-da-Silva, W., Onusic, L. M., \& Giglio, E. M. (2013). Rede de pesquisadores de finanças no Brasil: um mundo pequeno feito por poucos. Revista de Administração Contemporânea, 17(6), pp. 739-763.

Michels, C., \& Schmoch, U. (2014). Impact of bibliometric studies on the publication behaviour of authors. Scientometrics, 98(1), pp. 369-385. doi: 10.1007/s11192-013-1015-7. 
Moreno, J. L. (1993). Psicodrama. São Paulo: Ed. Cultrix.

Moreno, J. L. (1992). Quem sobreviverá?-Fundamentos da sociometria, psicoterapia de grupo e sociodrama (Who shall Survive? Foundations of Sociometry, Group Psychotherapy and Sociodrama).

Moreno, J. L., Bouza, J. G., \& Karsz, S. (1962). Fundamentos de la sociometría. Paidós.

Moreno, J. L. (1951). Sociometry, experimental method and the science of society. an approach to a new political orientation. Beacon House, Beacon, New York.

Murcia, F. D. R., \& Borba, J. A. (2008). Possibilites for inserting brazilian accounting research in the international scenario: a proposal for the assessment of scientific accountancy and auditing journals published in english and available in the CAPES journal portal. Revista Contabilidade \& Finanças, 19(46), pp. 30-43. doi: 10.1590/S1519-70772008000100004.

Nascimento, A. R. do, Junqueira, E., \& Martins, G. de A. (2010). Pesquisa acadêmica em contabilidade gerencial no Brasil: análise e reflexões sobre teorias, metodologias e paradigmas. Revista de Administração Contemporânea, 14(6), pp. 1113-1133. doi: 10.1590/S1415-65552010000700008.

Oliveira, E. K. F. de, \& Boente, D. R. (2012). Análise bibliométrica da produção científica recente sobre contabilidade gerencial. Revista Organizações em Contexto, 8(15), pp. 199-212. doi: 10.15603/19828756/roc.v8n15p199-212.

Oliveira, L. B. de., \& Ávila, M. G. (1999). Descentralização em unidades de negócio: o caso de uma empresa do setor financeiro. Revista de Administração Contemporânea, 3(1), pp. 127-146. doi: 10.1590/ S1415-65551999000100008.

Padoveze, C. L. (1999). O papel da contabilidade gerencial no processo empresarial de criação de valor. Caderno de Estudos, (21), pp. 01-16. doi: 10.1590/S1413-92511999000200003.

Pádua, E. M. M. de. (2004). Metodologia da pesquisa: abordagem teórico-prática. 10ª ed. Campinas: Papirus.

Ribeiro, H. C. M. (2015). Particularidades da produção acadêmica publicada na revista de administração e contabilidade da unisinos no período de 2004 a 2014. Revista Contabilidade Vista e Revista, 26(3), pp. 80-105.

Ribeiro, H. C. M., Costa, B. K., \& Ferreira, M. P. (2015). Governança corporativa nos esportes: análise dos últimos 23 anos de produção acadêmica em periódicos internacionais. Revista de Administração e Contabilidade da Unisinos, 12(2), pp. 135-154 doi: 10.4013/base.2015.122.05.

Ribeiro, H. C. M. (2014a). Corporate governance versus corporate governance: an international review: uma análise comparativa da produção acadêmica do tema governança corporativa. Revista Contemporânea de Contabilidade, 11(23), pp. 95-116. doi: 10.5007/2175-8069.2014v11n23p95.

Ribeiro, H. C. M. (2014b). Produção acadêmica dos temas governança corporativa e sustentabilidade: uma análise dos últimos 14 anos nos periódicos internacionais. Revista Economia \& Gestão, 14(35), pp. 5-34.

Ribeiro, H. C. M. (2014c). Quinze anos de produção acadêmica do tema contabilidade internacional: uma análise bibliométrica em periódicos brasileiros. Revista de Educação e Pesquisa em Contabilidade, 8(3), pp. 326-343. doi: 10.17524/repec.v8i3.1079.

Ribeiro, H. C. M. (2013). Contribuição do congresso USP ao estudo da área temática controladoria e contabilidade gerencial: uma bibliometria. Revista de Administração, Contabilidade e Economia, 12(2), pp. 709-746.

Ribeiro, H. C. M., Cirani, C. B. S., \& Freitas, E. J. da S. M. de. (2013). Análise da produção científica da Revista de Administração e Inovação. Revista de Administração e Inovação, 10(4), pp. 208-228. doi: 10.5773/rai.v10i4.1139. 
Ribeiro, R. R. M., \& Espejo, M. M. dos S. B. (2013). Evolução das pesquisas em contabilidade gerencial: uma análise das opções temáticas em teses e dissertações no Brasil. Enfoque: Reflexão Contábil, 32(1), pp. 49-63. doi: 10.4025/enfoque.v32i1.18114.

Riccio, E. L., Mendonça Neto, O. R. D., \& Sakata, M. C. G. (2007). Movimentos de teorias em campos interdisciplinares: a inserção de Michel Foucault na contabilidade. Revista de Administração Contemporânea, 11(SPE2), pp. 11-32. doi: 10.1590/S1415-65552007000600002.

Rocha, W., \& Guerreiro, R. (2010). Desenvolvimento de modelo conceitual de sistemas de custos: um enfoque institucional. Revista de Contabilidade e Organizações, 4(8), pp. 24-46. doi: 10.11606/rco. v4i8.34757.

Rossoni, L., "\& Guarido Filho, E. R. (2009). Cooperação entre programas de pós-graduação em administração no Brasil: evidências estruturais em quatro áreas temáticas. Revista de Administração Contemporânea, 13(3), pp. 366-390. doi: 10.1590/S1415-65552009000300003.

Rostampoor-Vajari, M. (2012). What Is Sociometry and How We Can Apply It in Our Life? Advances in Asian Social Science, 2(4), pp. 570-573.

Silveira, M. A. A. da, \& Bazi, R. E. R. (2010). Rede de Textos Científicos na Ciência da Informação: análise cienciométrica da institucionalização de um campo científico. Pesquisa Brasileira em Ciência da Informação e Biblioteconomia, 3(2).

Smith, D. R., \& Hazelton, M. (2008). Bibliometrics, citation indexing, and the journals of nursing. Nursing \& Health Sciences, 10(4), pp. 260-265. doi: 10.1111/j.1442-2018.2008.00414.x.

Souza, M. D., \& Ribeiro, H. C. M. (2013). Sustentabilidade ambiental: uma meta-análise da produção brasileira em periódicos de administração. Revista de Administração Contemporânea, 17(3), pp. 368396. doi: 10.1590/S1415-65552013000300007.

Spinak, E. (2013). Diccionario enciclopédico de bibliometría, cienciometría e informetría. Montevideo: UNESCO.

Tavares Araújo, E. A., \& Castro Silva, W. A. (2010). Pesquisa científica em contabilidade gerencial nos Ananpads de 2003 a 2008. Revista Universo Contábil, 6(3), pp. 29-44. doi: 10.4270/ruc.2010320.

Teixeira, A. J. C., Gonzaga, R. P., Santos, A. de V. S. M., \& Nossa, V. (2011). A utilização de ferramentas de contabilidade gerencial nas empresas do Estado do Espírito Santo. Brazilian Business Review, 8(3), pp. 108-127.

Tsai, H-H. (2013). Knowledge management vs. data mining: Research trend, forecast and citation approach. Expert Systems with Applications, 40(8), pp. 3160-3173. doi: 10.1016/j.eswa.2012.12.029.

Vieira, E., \& Gomes, J. (2009). A comparison of Scopus and Web of Science for a typical university. Scientometrics, 81(2), pp. 587-600. doi: 10.1007/s11192-009-2178-0.

Wanderley, C. D. A., \& Cullen, J. (2012). A case of management accounting change: the political and social dynamics. Revista Contabilidade \& Finanças, 23(60), pp. 161-172. doi: 10.1590/S151970772012000300002 .

Wasserman, S., \& Faust, K. (1994). Social network analysis: methods and applications. Cambridge: Cambridge University Press.

Weingart, P. (2005). Impact of bibliometrics upon the science system: Inadvertent consequences? Scientometrics, 62(1), pp. 117-131. doi: 10.1007/s11192-005-0007-7.

Zauber, A. G., O’Brien, M.J., Winawer, S.J., Ho, M.N., Gottieb, L.S. \& Stemberg, S.S. (2012). Colonoscopic polypectomy and long-term prevention of colorectal-cancer deaths. New England Journal of Medicine, 366(8), pp. 687-696. doi: 10.1056/NEJMoa1100370. 